\title{
Efficacy of selected complementary and alternative medicine interventions for chronic pain
}

Gabriel Tan, PhD, ABPP ; ${ }^{1-2 *}$ Michael H. Craine, PhD; ${ }^{3-4}$ Matthew J. Bair, MD, MS; ${ }^{5}$ M. Kay Garcia, DrPH, MSN, RN, LAc; ${ }^{6-7}$ James Giordano, PhD; ${ }^{8-9}$ Mark P. Jensen, PhD; ${ }^{10}$ Shelley M. McDonald, MD; ${ }^{5}$ David Patterson, PhD, ABPP; ${ }^{10}$ Richard A. Sherman, PhD; ${ }^{11}$ Wright Williams, PhD; ${ }^{12-13}$ Jennie C. I. Tsao, PhD $^{14}$ ${ }^{1}$ Anesthesiology Care Line, Department of Anesthesiology, Michael E. DeBakey Department of Veterans Affairs (VA) Medical Center (VAMC), Houston, TX; ${ }^{2}$ Department of Physical Medicine and Rehabilitation, Baylor College of Medicine, Houston, TX; ${ }^{3}$ Health Psychology, Patient Focused Care Service, Denver VAMC/VA Eastern Colorado Health Care System, Denver, CO; ${ }^{4}$ Department of Physical Medicine and Rehabilitation, University of Colorado Health Sciences Center, Denver, CO; ${ }^{5}$ Health Services Research and Development Center of Excellence on Implementing Evidence-Based Practice, Richard L. Roudebush VAMC, Indianapolis, IN; ${ }^{6}$ Department of Anesthesiology and Pain Medicine, University of Texas M. D. Anderson Cancer Center, Houston, TX; ${ }^{7}$ American College of Acupuncture and Oriental Medicine, Houston, TX; ${ }^{8}$ Center for Clinical Bioethics and Division of Palliative Medicine, Georgetown University Medical Center, Washington, DC; ${ }^{9}$ Samueli Institute, Alexandria, VA; ${ }^{10}$ Department of Rehabilitation Medicine, University of Washington School of Medicine, Seattle, WA; ${ }^{11}$ Behavioral Medicine Research and Training Foundation, Port Angeles, WA; ${ }^{12}$ Mental Health Care Line, Michael E. DeBakey VAMC, Houston, TX; ${ }^{13}$ Department of Psychiatry and Behavioral Science, Baylor College of Medicine, Houston, TX; ${ }^{14}$ University of California Los Angeles (UCLA) Pediatric Pain Program, Department of Pediatrics, David Geffen School of Medicine at UCLA, Los Angeles, CA

\begin{abstract}
Complementary and alternative medicine (CAM) is a group of diverse medical and healthcare systems, therapies, and products that are not presently considered part of conventional medicine. This article provides an up-to-date review of the efficacy of selected CAM modalities in the management of chronic pain. Findings are presented according to the classification system developed by the National Institutes of Health National Center for Complementary and Alternative Medicine (formerly Office of Alternative Medicine) and are grouped into four domains: biologically based medicine, energy medicine, manipulative and body-based medicine, and mind-body medicine. Homeopathy and acupuncture are discussed separately as "whole or professionalized CAM practices." Based on the guidelines of the Clinical Psychology Division of the American Psychological Association, findings indicate that some CAM modalities have a solid track record of efficacy, whereas others are promising but require additional research. The article concludes with recommendations to pain practitioners.
\end{abstract}

Abbreviations: $\mathrm{APA}=$ American Psychological Association, $\mathrm{CAM}=$ complementary and alternative medicine, $\mathrm{CBT}=$ cognitive-behavioral therapy, $\mathrm{CDC}=$ Centers for Disease Control and Prevention, CES = cranial electrotherapy stimulation, CRPS = complex regional pain syndrome, EEG = electroencephalogram, IBS = irritable bowel syndrome, LBP = low back pain, MBSR = Mindfulness-Based Stress Reduction, MBT $=$ mind-body therapy, NCCAM = National Center for Complementary and Alternative Medicine, $\mathrm{OA}=$ osteoarthritis, $\mathrm{OAM}=$ Office of Alternative Medicine, PEMF = pulsed electromagnetic field, PMR = progressive muscle relaxation, RCT $=$ randomized controlled trial, $\mathrm{sEMG}=$ surface electromyogram, $\mathrm{SMT}=$ spinal manipulation therapy, TCM = traditional Chinese medicine, TENS = transcutaneous electrical stimulation, TMJ = temporomandibular joint, TT = therapeutic touch.

* Address all correspondence to Gabriel Tan, PhD, ABPP; Anesthesiology Care Line (145), Michael E. DeBakey VAMC, 2002 Holcombe Blvd, Houston, TX 77030; 713-794-8794; fax: 713-794-7674. Email: tan.gabriel@med.va.gov

DOI: 10.1682/JRRD.2006.06.0063 
Key words: biologically based medicine, chronic pain, complementary and alternative medicine, efficacy, energy medicine, manipulative and body-based medicine, mind-body medicine, pain management, rehabilitation, whole or professionalized CAM practices.

\section{INTRODUCTION}

\section{Definition of Complementary and Alternative Medicine}

Complementary and alternative medicine (CAM) is a group of diverse medical and healthcare systems, therapies, and products that are not presently considered part of conventional medicine. They are not generally provided by U.S. hospitals and clinics or widely taught in medical schools [1].

\section{Prevalence and Popularity of Complementary and Alternative Medicine Use}

CAM modalities are widely used by the U.S. public. According to the Centers for Disease Control and Prevention (CDC), 62 percent of adults used some form of CAM during the past 12 months when the definition of CAM included prayer specifically for health reasons and 36 percent when prayer was excluded [2]. The most frequent conditions associated with CAM use included back pain, neck pain, joint pain, stiffness, anxiety, and depression (the latter two are commonly associated with chronic pain). CAM use increased substantially during the 1990s. The U.S. public spent an estimated \$36 to $\$ 47$ billion on CAM in 1997 alone [3]; between $\$ 12.2$ and $\$ 19.6$ billion were paid out-of-pocket for the services of CAM providers such as chiropractors, acupuncturists, and massage therapists. These fees are more than the U.S. public paid out-of-pocket for all hospitalizations in 1997 and half the amount of all out-of-pocket physician services for traditional care [4].

\section{Purpose of This Article}

Despite the immense popularity of CAM, its efficacy is controversial. Many view CAM as encompassing unproven therapies of questionable efficacy. This article comprehensively reviews the efficacy of various CAM modalities in the management of chronic pain. The review has been restricted to chronic pain because of the wider availability of efficacious traditional interventions for acute pain. However, as our effort progressed, we realized that the relevant literature encompasses a wide range of CAM modalities and a large variety of chronic pain conditions. Thus, great variation exists regarding the number, type, and quality of trials for each specific CAM approach, with some modalities (e.g., acupuncture) possessing a large literature and many other modalities (e.g., craniosacral therapy) having been the subject of very few trials. Certain specific pain complaints (e.g., low back pain [LBP]) have been extensively investigated, whereas other chronic pain conditions (e.g., complex regional pain syndrome [CRPS]) have only been studied in a handful of trials. In light of the inherent inconsistencies and vastness of the extant literature, we modified the aim of this article to a more conservative and manageable goal: to summarize the evidence for selected CAM modalities that have been applied to the management of a wide range of chronic pain complaints, highlight areas for future study, and provide general guidelines for clinicians. Thus, we reviewed and summarized the empirical evidence for each selected modality.

In addition to reviewing the efficacy data, we reviewed the mechanism of action for each selected modality, although this is not a major focus of the article. Similar to their counterparts in more traditional chronic pain interventions, very little is known about the actual mechanism of action for CAM modalities. Most of what we provide here is a summary of the purported or suspected mechanisms of action.

The selection of modalities for inclusion in this review was based on several factors: the modality had been the subject of at least one controlled study or several strong primary efficacy studies, was commonly known and publicly available, and was not already a common service in typical healthcare settings. Thus, prayer and spirituality, despite their popularity according to the CDC study [2], were excluded because of the lack of published efficacy studies on chronic pain. Transcutaneous electrical stimulation (TENS), cognitive-behavioral therapy (CBT), and relaxation therapy, despite being listed on the Web site of the National Center for Complementary and Alternative Medicine (NCCAM) (formerly the Office of Alternative Medicine [OAM]), were excluded since they are widely used and no longer considered CAM by practitioners.

\section{Methodology}

To synthesize the vast amount of data on the efficacy of CAM, we used combined methods to select studies for inclusion in this review. We searched computerized databases including MEDLINE, PsychINFO, CINAHL, and 
the Cochrane Library between 1966 and July 2006 using the search terms "pain" and the specific CAM modality of interest (e.g., "acupuncture”). To be as inclusive as possible, we did not use search terms that specified the type of pain complaint. Each article uncovered by this search strategy was manually checked to determine whether the study focused on a chronic pain condition. Articles that investigated acute pain (e.g., pain related to injury or medical procedures) or disease-related pain (e.g., cancer pain) were excluded. Only studies that included pain severity and/or functional disability as key outcomes were included. Only findings from controlled trials, including randomized controlled trials (RCTs), review articles, and meta-analyses (limited to human studies reported in English) were included. Because of the very large number of studies uncovered by this search strategy, we condensed and synthesized the literature using the following steps. For those CAM modalities and chronic pain conditions in which peer-reviewed systematic reviews (e.g., Cochrane reviews, meta-analyses) were identified, the findings were summarized and the authors' conclusions described. Primary trials that were excluded by these review authors because of methodological or other limitations were not included. However, findings from relevant primary studies published since these reviews appeared were included. Only those CAM modalities and chronic pain conditions that were the subject of at least one controlled trial were included in this article.

\section{Criteria for Evaluation of Efficacy}

Based on the guidelines of the Clinical Psychology Division of the American Psychological Association (APA) (Figure), this review evaluates evidence for the efficacy of various CAM modalities for treatment of chronic pain [5-6]. One should note that most prior reviews in this area have focused on only one or two CAM modalities and have included only one type of chronic pain complaint. Since we aimed to cover a broad range of CAM modalities and chronic pain conditions, we did not incorporate specific criteria typically used for evaluation of the methodological quality of individual trials (e.g., Jadad scores). This decision was based on the fact that the various reviews and meta-analyses included in this article used different rating systems to evaluate the quality of the trials and we could not determine the best way to reconcile these different systems. Ratings for the efficacy of each reviewed CAM modality based on APA guidelines are depicted in the Figure.

\section{Organization of This Article}

The findings are presented according to the classification system developed by the OAM/NCCAM that grouped CAM therapies into four domains: biologically based medicine, energy medicine, manipulative and body-based medicine, and mind-body medicine. Homeopathy and acupuncture are discussed separately since they are recognized by NCCAM as "whole or professionalized CAM practices." For each modality, the findings of comprehensive reviews and/or meta-analyses are summarized first (where available) and followed by the results of primary trials published after these reviews appeared.

\section{BIOLOGICALLY BASED MEDICINE}

This section focuses on dietary supplements for treating chronic pain. As defined by NCCAM, dietary supplements include vitamins, minerals, herbal preparations, botanicals, amino acids, enzymes, and glandulars. A recently published systematic review evaluated three different herbal remedies for treating LBP: devil's claw, white willow bark, and topical cayenne [7]. Several trials in the review found devil's claw to be superior to placebo for short-term pain relief in patients with acute exacerbations of chronic LBP. A single trial found white willow bark superior to placebo for short-term pain relief. Evidence on the efficacy of cayenne was mixed. Long-term outcomes were not included in this review.

The 84 additional studies that we identified addressed chronic pain conditions including rheumatoid arthritis and osteoarthritis (OA) (50 studies), back pain (7 studies), neuropathic pain (4 studies), and various other conditions, such as prostatitis and sickle cell pain (23 studies). The most commonly tested supplement was combined glucosamine and chondroitin sulfate (22 studies). A recent large-scale trial investigating glucosamine and chondroitin sulfate suggested that the combination may be safe and effective for patients with moderate to severe knee OA pain [8]. Other commonly tested supplements included aromatherapy/aromatic oils (9 studies), fatty acids/fish oils (7 studies), and cannabis derivatives (4 studies).

The 84 trials ranged in length from 2 days to 3 years and included from 8 to 555 subjects. Sixty-three studies 


\section{Level 1: Not Empirically Supported.}

This classification is assigned to those treatments that have only been described and supported by anecdotal reports and/or case studies in non-peer reviewed journals.

\section{Level 2: Possibly Efficacious.}

This classification is considered appropriate for those treatments that had sufficient statistical power in at least one study, well-identified outcome measures, but lacked randomized assignment to control condition internal to study.

\section{Level 3: Probably Efficacious.}

Treatment approaches that have been evaluated and shown to produce beneficial effects in multiple observational studies, clinical studies, wait list control studies, and within-subject and between-subject replication studies merit this classification.

\section{Level 4: Efficacious.}

In order to be considered "efficacious," a treatment must meet the following criteria:

(a) In comparison with no-treatment control group, alternative treatment group, or sham (placebo) control utilizing randomized assignment, investigational treatment is shown to be statistically significantly superior to control condition or investigational treatment is equivalent to treatment of established efficacy in study with sufficient power to detect moderate differences.

(b) Studies have been conducted with population treated for specific problem, from whom inclusion criteria are delineated in reliable, operationally defined manner.

(c) Study used valid and clearly specified outcome measures related to problem being treated.

(d) Data are subjected to appropriate data analysis.

(e) Diagnostic and treatment variables and procedures are clearly defined in manner that permits replication of study by independent researchers.

(f) Superiority or equivalence of investigational treatment has been shown in at least two independent studies (LaVaque T, Hammond D, Trudeau D, Monastra V, Perry J, Lehrer P, Matheson D, Sherman R. Template for developing guidelines for the evaluation of the clinical efficacy of psychophysiological evaluations. Appl Psychophysiol Biofeedback. 2002;27(4):273-81).

\section{Level 5: Efficacious and Specific.}

To meet criteria for this classification, treatment needs to be statistically superior to credible sham therapy, pill, or bona fide treatment in at least two independent studies.

\section{Figure.}

Clinical Psychology Division of American Psychological Association guidelines on treatment efficacy. Source: Chambless DL, Baker MJ, Baucaom DH, Beutler LE, Calhoun KS, Crits-Christoph P, Daiuto A, DeRubeis R, Detweiler J, Haaga DAF, Johnson SB, McCurry S, Mueser KT, Pope KT, Sanderson WC, Shoham V, Stickle T, Williams DA, Woody SR. Update on empirically validated therapies II. Clin Psychol. 1998;51(1):3-16; and Chambless DL, Hollon SD. Defining empirically supported therapies. J Consult Clin Psychol. 1998;66(1):7-18 [MID:9489259].

compared supplements with placebo, and the rest involved comparisons with an active treatment control. Of the 84 trials, 53 indicated that pain significantly improved with the dietary supplement compared with the control or comparison group. Twenty-four studies demonstrated no significant difference between treatment and control or favored active treatment, such as ibuprofen or rofecoxib, and seven studies had mixed results.

In summary, studies on the efficacy of dietary supplements varied extensively in the remedies tested and pain conditions treated. A recent systematic review found clinical trial evidence for the efficacy of devil's claw and white willow bark in acute exacerbations of chronic LBP but mixed results with the use of cayenne [7]. Most clinical trials (63\%) showed a statistically significant effect on pain compared with placebo. However, many studies were limited by small sample sizes and short trial lengths. A recent large-scale trial suggested that combined glucosamine and chondroitin sulfate may be safe and effective for patients with moderate to severe knee OA pain [8]. Thus, the evidence tends to favor glucosamine and chondroitin sulfate for management of knee pain. Other biologically based therapies were not included because of the 
absence of primary studies and/or at least one controlled study.

\section{ENERGY MEDICINE}

According to NCCAM, the two types of energy therapies are bioelectromagnetic-based therapies that involve the unconventional use of electromagnetic fields, such as pulsed fields, magnetic fields, or alternating-current/ direct-current fields, and biofield therapies that are intended to affect the energy fields that purportedly surround and penetrate the human body. NCCAM notes that the existence of biofields has not been scientifically proven. TENS has been excluded since it is widely used in hospitals and pain-care settings and is no longer considered CAM by most pain practitioners.

\section{Pulsed Electromagnetic Fields}

Pulsed electromagnetic field (PEMF) generators come in two major types. The relatively low-power devices are usually wearable, battery-powered, and designed for nearly continuous use throughout a patient's treatment. Relatively high-power devices, such as the Diapulse Model 103 (Diapulse Corporation of America, Great Neck, New York) that produces sufficient power to light a $40 \mathrm{~W}$ lightbulb placed within its field, are designed for use several times a day. All the studies using relatively high-power PEMF used a Diapulse Model 103 set to produce $975 \mathrm{~W}$ at $27.12 \mathrm{MHz}$ in $65 \mu$ s bursts pulsing 600 times a second. The head of the device is set so that its cone-shaped field points at each inner thigh for a half hour each (1 hour total) once a day.

In reviewing the published research on the use of PEMF for headache, Vincent et al. concluded that combined small double-blind, placebo-controlled and open clinical trials showed that PEMF could significantly reduce chronic migraine headache activity by at least 80 percent. Subsequent follow-ups showed that the effects could be sustained for at least 16 months. ${ }^{*}$ Two reviewers discussed the use of PEMF for OA. Fini et al. reviewed the PEMF literature and found positive effects on cartilage cell and tissue cultures in in vitro and in vivo animal

\footnotetext{
*Vincent W, Andrasik F, Sherman R. Headache treatment with pulsing electromagnetic fields: A review of the literature on an emerging form of alternative treatment. Unpublished observations; 2006.
}

studies and cited three RCTs that found improvements in OA in clinical studies [9]. They concluded that PEMF can potentially modify the complex pathological processes that occur in tissue damaged by OA. Hulme et al. reviewed studies involving the use of PEMF in OA treatment [10]. They found small to moderate but significant results in knee OA patients and more limited but positive results in cervical spine OA patients. Hulme et al. concluded that PEMF may significantly improve knee OA pain but suggested that further studies be conducted.

Several randomized, placebo-controlled trials were conducted with low-power PEMF devices that were worn near the head for approximately 1 month [11-12]. One study found symptom relief for 77 percent of participants in the treatment group, with 8 percent of controls reporting minor relief and 1 percent reporting moderate relief [11]. The study did not report any follow-up data. In another study, one-half of the subjects receiving the PEMF treatment reported at least a 25 percent decrease in days with headache, whereas one-quarter of the controls reported a similar reduction [12]. Again, no follow-up data were reported.

Four studies were identified that examined the effects of high-power PEMF on migraine headaches [13-14]. The first demonstrated a nearly tenfold decrease in headache activity that was maintained from 6 to 18 months follow-up. The second study was a double-blind, placebocontrolled crossover study that failed when all but one participant who received PEMF first refused to cross over because his or her headaches had decreased dramatically. As in the first study, headache activity substantially decreased and this decrease was maintained at 3 months follow-up. The third study was a double-blind, placebo-controlled study in which PEMF reduced headaches substantially more than placebo. Finally, a fourth study demonstrated that patients could use the device in their homes with good clinical results.

In these studies, tension-headache patients showed little change in headache activity after exposure to the device and patients with mixed tension-migraine headaches only showed changes in the migraine component. Moreover, these studies showed a clear dose-response relationship: migraine patients exposed for only 2 weeks showed fewer decrements in headache activity than those exposed for 3 weeks, and migraine patients exposed to the device's half-power showed less effect than similar patients exposed for the same amount of time to the device's full power. None of the studies reported negative 
side effects. PEMF has now been in use for more than 3 decades and no negative side effects have been reported [15].

Four RCTs applied PEMF to the treatment of knee OA [16-19], two to patients with cervical spine OA $[18,20]$, and one to patients with temporomandibular joint (TMJ) disorder [21]. All RCTs were double-blind treatments that used sham PEMF in the control group. The first study that used PEMF to treat knee OA included 83 patients and found significant improvements in pain and stiffness in the patients under age 65 [16]. The second knee OA study applied PEMF to 36 patients and found reduced impairment in activities of daily living and improved knee function [17]. The third knee OA study applied PEMF to 86 patients and found significant improvements in pain and pain on motion [18]. The final knee OA study applied PEMF to 25 patients and found decreased pain and improved functional performance [19]. The authors concluded that the method warrants further investigation as a means of improving symptoms in patients with OA. Trock et al. also treated 81 patients with cervical spine OA but found somewhat lesser improvements among cervical spine versus knee OA patients [18]. In another study of cervical pain, Sutbeyaz et al. applied PEMF to 34 patients with cervical spine $\mathrm{OA}$ and found significant improvements in neck pain and disability among the experimental but not the sham-treatment control group [20]. Finally, one author applied PEMF to the treatment of 42 patients with TMJ disorder and found that PEMF had no specific treatment effects [21]. Despite the relatively small number of patients treated in these studies, this research suggests that PEMF is probably efficacious for treatment of knee OA and possibly efficacious for treatment of cervical spine OA.

In summary, although relatively few studies have examined the efficacy of PEMF, the research to date suggests that this treatment may be highly effective for patients with migraine, but not tension-type, headaches. However, given the paucity of controlled studies, the small number of participants, and the rarity of follow-up data, the overall efficacy of PEMF treatments for headache would still only be rated as probably efficacious based on the APA criteria for efficacy. PEMF is probably efficacious for treatment of knee OA and possibly efficacious for treatment of cervical spine OA. Moreover, the device is relatively inexpensive, appears to have no shortterm side effects, and can be easily applied by patients or technicians.

\section{Cranial Electrotherapy Stimulation}

Cranial electrotherapy stimulation (CES) involves the delivery of a low-level electrical current via external skin-surface electrodes (usually placed on the ear[s]). The low-level current is ordinarily subthreshold for sensory detection and appears to engage electrical and neurochemical mechanisms that affect network electrophysiological activity of brain systems and mediate arousal, sensory processing, and thus, pain and pain modulation.

No systematic reviews of the use of CES with chronic pain were identified. However, several welldesigned studies of CES treatment have been conducted with various patient populations. In a double-blind study, CES was compared to dental anesthesia, and while results varied, favorable outcomes were generally reported for CES versus sham CES [22]. Another study examined electroencephalogram (EEG) spectra and pain relief with a two-part double-blind approach that compared CES with sham control and other forms of central stimulation (i.e., Liss Stimulator) [23]. In this study, results also varied, yet the authors concluded that CES produced EEG spectral smoothing and pain relief that was superior to the sham control or comparison treatment. Naveau et al. used a randomized double-blind protocol to evaluate the capacity of CES to reduce the required analgesic dose of fentanyl in rectal cancer patients undergoing Nd:YAG laser treatment [24]. The authors reported that CES treatment enabled a 31 percent decrease in the dose of fentanyl required for pain relief.

A double-blind, placebo-controlled study of 60 patients with fibromyalgia indicated that CES, as compared with sham treatment or waiting-list control, reduced tender points by 28 percent and self-rated pain by 27 percent [25]. More recently, a double-blind control study comparing CES with sham treatment for 38 patients with pain associated with spinal cord injury concluded that CES effectively reduces pain and pain interference [26]. To summarize, several studies have found that CES effectively reduces pain. Although this work is somewhat incipient, CES shows considerable promise as both a complementary modality to other forms of therapeutic interventions and as a stand-alone approach to the treatment of particular types of pain. Consequently, CES would be rated as possibly efficacious for pain relief.

\section{Therapeutic Touch/Healing Touch}

Therapeutic touch (TT) or "healing touch" is derived from the ancient technique of laying on of hands. The goal is promotion or maintenance of the balance of vital 
energy fields in the body. It is based on the notion that the therapist's healing force affects the patient's recovery. Typically, the therapist passes his or her hands over the patient (without direct physical contact) to identify and correct energy imbalances. Several reviews of TT exist [27-30], but none focused specifically on its value for pain relief. In addition, many of the studies included in these reviews were uncontrolled and/or unpublished (e.g., abstracts, dissertations) or not peer reviewed (e.g., book chapters).

The results of one study [31] included in the Cochrane review on noninvasive treatments for headache pain [32] led the review authors to conclude that moderate evidence shows that TT is superior to placebo TT for reduction of tension-type headache pain within a few hours of a single treatment. Other published controlled trials have revealed greater reductions in pain for TT, relative to mock TT, for knee OA [33] and mixed chronic musculoskeletal problems [34]. However, negative findings have also been reported. One study found that progressive muscle relaxation (PMR) was more effective than TT for pain related to degenerative arthritis [35], another found that TT was not superior to education for fibromyalgia pain [36], and a third found that TT was not more beneficial than relaxation when both were delivered as adjuncts to CBT in 12 patients with mixed chronic pain [37]. In general, the quality of the positive studies was poor because of numerous methodological limitations (e.g., insufficient sample size). Taking into account the null findings just discussed, one can conclude that insufficient evidence exists for the use of TT for chronic pain, with the exception of tension-type headaches. Future studies should include larger sample sizes, and if mixed groups of patients are studied, care should be taken to ensure equivalence of clinical factors across groups.

\section{Reiki}

Reiki is a Japanese term that refers to "universal life energy." Reiki is based on the notion that when spiritual energy is channeled through a Reiki practitioner, the patient's spirit is healed, which in turn heals the patient's physical body. The main distinction between Reiki and TT is that Reiki therapists have physical contact with the body. We located three studies on the application of Reiki for pain, although only one study included a control group. The uncontrolled studies found improvements in mixed chronic pain symptoms [38] and pain related to human immunodeficiency virus [39]. In the only con- trolled trial, Reiki showed modest evidence for shortterm reduction of cancer pain [40]. To summarize, little evidence from controlled trials currently supports the use of Reiki for pain.

\section{Qigong/Qi Therapy}

The Chinese term qi means "vital energy," and the term gong means "training." Thus, qigong is a component of traditional Chinese medicine (TCM) that combines movement, meditation, and regulation of breathing for enhanced flow of qi in the body. The improved flow of qi is thought to lead to health benefits including pain reduction. Four studies were located that examined the effects of qigong or qi therapy on pain. In the first study, patients with CRPS type I showed short-term benefits from training with a qigong master compared with a sham master but these gains were attenuated by the 6- to 10-week follow-ups [41]. The other three studies on qi therapy were conducted by the same research group on elderly participants (60 years or older) with mixed chronic pain symptoms. In these studies, the qi therapy involved a practitioner adjusting the patients' qi; patients did not engage in exercises or movement. In two of these studies [42-43], patients who received qi therapy reported less pain than usual-care controls. The third study found that patients who received qi therapy reported less pain, anxiety, depression, and fatigue and exhibited lower blood pressure compared with those who received sham qi therapy [44]. Overall, qi therapy could be rated as possibly to probably efficacious for treatment of chronic pain.

\section{MANIPULATIVE AND BODY-BASED MEDICINE}

As defined by NCCAM, manipulative and bodybased medicine includes chiropractic and massage therapy, which are subsequently reviewed. Chiropractic manipulation and various forms of massage therapies are included since they are modalities commonly known to the public and available to patients.

\section{Chiropractic Manipulation}

Spinal manipulation therapy (SMT), practiced primarily by chiropractors, is the most popular CAM therapy for LBP [45]. SMT has been licensed in all 50 states since 1974 and is covered by most insurance plans. However, conflicting results of studies evaluating the efficacy 
of SMT have led to confusion about whether SMT is superior to standard therapy.

A recent systematic Cochrane review of SMT for LBP found that SMT had clinically and statistically significant benefits when compared with either sham manipulation or various LBP therapies previously determined to be ineffective or harmful (e.g., traction, bed rest, home care, topical gel, or no treatment) [46]. When compared with other recommended treatments for LBP, including analgesics, physical therapy, exercises, or back school, SMT did not show any statistically significant benefits. Another recent review also found that SMT had statistically significant benefits only when compared with sham or ineffective therapies [47]. No evidence was found that SMT was any more or less effective than conventional therapies for acute or chronic LBP.

A total of 47 studies met our search criteria. The majority (25 studies) evaluated SMT for subacute or chronic LBP. Cervical spine pain was also commonly studied (13 studies). Nine articles reported on SMT for various pain conditions, including fibromyalgia, carpal tunnel syndrome, migraine and tension-type headaches, coccydynia, dysmenorrhea, shoulder dysfunction, and total abdominal hysterectomy. Of the 47 studies, 20 tested SMT combined with other modalities such as heat, exercise, or medication. Control or comparison groups varied across studies. Placebo-controlled or sham SMT was compared in one-third of studies (15 studies). Thirteen studies involved exercise or stabilization, nine involved usual care as prescribed by a primary or specialty care physician, and ten included medication or electrical stimulation. Overall, 18 studies demonstrated a beneficial effect of SMT over the comparison group for pain or pain-related disability. In studies comparing SMT with placebo or sham, five showed statistically significant improvement in pain or disability as a result of SMT. The results demonstrated the benefit of SMT over exercise or stabilization, usual care, and medication or electrical stimulation in 23, 44, and 60 percent of studies, respectively.

In summary, evidence from two recent systematic reviews indicates that SMT is more effective than sham manipulation and treatments such as bed rest and traction but no more effective than other recommended LBP treatments. Consequently SMT should be considered probably efficacious for treating LBP. Multiple studies have shown that SMT may reduce pain severity and disability in chronic pain conditions other than LBP but should be viewed cautiously at this time. Future studies of SMT for pain conditions should adhere to rigorous methodological guidelines and identify which patients are most likely to benefit from this pain-management approach.

\section{Massage Therapy}

Massage therapy is defined as soft-tissue manipulation by trained therapists for therapeutic purposes [48]. Massage therapy may take different forms, including Swedish, reflexology, Shiatsu, Rolfing, and craniosacral. Massage is typically used as adjunct therapy that prepares the patient for exercise or other interventions rather than as the main treatment [49].

Our search identified 21 studies on the application of massage for LBP (8 studies), headache pain (2 studies), neck pain (1 study), shoulder pain (3 studies), fibromyalgia (4 studies), and mixed chronic pain (3 studies). In their comprehensive review, the Cochrane Collaboration recently reported that massage was (1) superior to relaxation [50], acupuncture [45], and self-care education [45] for LBP; (2) equal to corsets [51-52] and exercises [53]; and (3) inferior to SMT [51-52,54-55] and TENS [56]. One should note, however, that in some cases, such as acupuncture, these conclusions are based on only one RCT. The Cochrane Collaboration also reviewed noninvasive physical treatments for chronic/recurrent headache [32] but only one trial (reported in two studies [5758]) examined massage. This trial found SMT to be superior to massage for cervicogenic headache [57-58], whereas another trial not included in the Cochrane review found greater pain reduction for massage relative to acupuncture in patients with migraine but not tensiontype or combined headaches [59]. Thus, the findings for headaches are mixed.

The single study on neck pain found that by 3-month follow-up, pain reduction did not differ between acupuncture and massage [60]. All three studies on shoulder pain reported significant improvements in pain compared with the no-treatment control [61-63]. For fibromyalgia, two studies conducted by the same group found massage to be superior to TENS [64] and PMR [65]. The two other fibromyalgia studies revealed greater pain reduction for massage versus no treatment by 6-month followup [66] and no benefits for massage compared with usual care (i.e., standard care provided by physicians including medications) [67]. For mixed chronic pain, one study found that massage led to less pain than usual care [68] but the other two studies reported no benefits of massage 
over relaxation (at 3-month follow-up) [69] or mediation and usual care (at 1-month follow-up) [70].

To summarize, massage therapy is useful for pain relief in numerous chronic pain conditions, particularly LBP and shoulder pain. The authors of a Cochrane review concluded that massage therapy may benefit patients with subacute and chronic nonspecific LBP, particularly when combined with exercise and education [49]. Less support exists for the use of massage therapy for patients with headache pain, neck pain, or fibromyalgia, although one study found that massage may be superior to acupuncture for migraine but not tension-type headaches. On this basis, massage therapy is rated as efficacious for LBP, probably efficacious for shoulder pain, and possibly efficacious for fibromyalgia and neck pain.

\section{Craniosacral Therapy}

Proponents of craniosacral therapy maintain that movement restrictions in the cranial structures of the skull adversely affect impact rhythmic impulses conveyed through the cerebral spinal fluid from the cranium to the sacrum [71]. Thus, craniosacral therapy is a form of massage that uses gentle pressure on the plates of the patient's skull. Few controlled studies have been conducted on craniosacral therapy, and a recent review concluded that evidence to support its use is insufficient [71]. However, none of the studies in this review included pain as an outcome measure. Only one study relevant to the current review was located. This study examined the CV-4 craniosacral technique for tensiontype headaches [72]. The CV-4 technique moves with the narrowing and widening of the skull, or the cranial rhythm; the basis of the technique is compression of the fourth ventricle [72]. For additional details regarding the CV-4 technique, see the book by Upledger and Vredevoogd [73]. Patients who received CV-4 reported less pain intensity and negative affect than the controls. The authors of a recent review of manual therapies for tension-type headaches concluded that moderate evidence indicates that the CV-4 technique exerts a beneficial effect on pain related to tension-type headaches [74]. Nevertheless, additional large-scale trials that include follow-up assessments are warranted before recommendations regarding application of the $\mathrm{CV}-4$ technique to pain relief can be made.

\section{MIND-BODY MEDICINE}

Mind-body therapies (MBTs) cover a wide array of modalities and procedures. Relaxation is a common element of many MBTs and will not be covered as a separate modality in this review. CBTs are now widely accepted in pain management and therefore also will not be covered.

\section{Meditation}

Meditation has its roots in spiritual practice [75-77]. Meditation can be defined as intentional self-regulation of attention to promote a specific mental focus and awareness of internal or external experiences [78]. The two general types of meditation are concentrative and mindfulness [79]. Concentrative meditation uses a specific focus as the object of attention, such as a visual image, the counting of breaths, or the repetition of a specific word or phrase. Mindfulness meditation does not limit attention to a particular object but involves increased attention and awareness to the fullness of the current experience and present reality [80]. In chronic pain, mindfulness meditation is used for promoting detached observation of the pain and awareness of the moment-to-moment primary sensations as separate events with accompanying thoughts about pain [81]. A model of Mindfulness-Based Stress Reduction (MBSR) was introduced for pain management more than 20 years ago [82]. A systematic review of MBT for pain management [83] concluded that MBSR is a promising intervention for chronic LBP and heterogeneous pain [81-82,84]. A recent meta-analysis of MBSR included five studies of physical conditions, including two studies of fibromyalgia and one of general chronic pain [85]. The meta-analysis estimated a mean effect size of 0.53 (95\% confidence interval 0.23-0.81), indicating moderate effects of MBSR.

Our search also discovered five additional RCTs that examined the effects of meditation on LBP (two studies), fibromyalgia (one study), mixed musculoskeletal pain (one study), and irritable bowel syndrome (IBS) (one study). One LBP study found significant improvements among patients who engaged in meditation compared with no improvements in a standard-care group [86]. Because of attrition rates of 44 and 17 percent in the meditation and control groups, respectively, power for between-group comparisons was inadequate. The other study on LBP showed no significant differences in pain reduction between patients who received breath therapy 
(i.e., integrated approach of body awareness, breathing, meditation, and movement) compared with physical therapy [87]. The single study on fibromyalgia compared MBSR and qigong with an education control group $[78,88]$. Nearly 50 percent of patients from both groups dropped out and no group differences in pain were found at any assessment point. For mixed musculoskeletal pain, MBSR was compared with massage and standard care [70]; by 1-month follow-up, the groups did not differ in pain intensity or pain unpleasantness. The single study on IBS found significant improvements in general gastrointestinal symptoms [89] but no differences in pain symptoms in patients assigned to concentrative meditation versus wait-list control [90].

In summary, existing evidence is not strong enough to support routine use of meditation for pain management but supports its probable efficacy for patients interested in it as an adjunct to other care. Meditation is thus similar to other MBTs, and outcomes are likely to be improved by assessment of patient variables such as expectations and readiness to change [91]. The current studies used mainly female samples and may not generalize to males. A study of concentrative meditation conducted at the San Diego Department of Veterans Affairs Medical Center with a predominately male group demonstrated improvement on stress, anxiety, quality of life, and spiritual wellbeing measures [92]. With the exception of breath therapy, which used touch in the intervention, none of the studies reviewed indicated adverse reactions to meditation training. However, clinicians should be aware of the potential for some increased anxiety, which has been shown in relaxation studies [93].

\section{Hypnosis}

Hypnosis “. . . typically involves an introduction to the procedure during which the subject is told that suggestions for imaginative experiences will be presented" and that following this introduction "... one person (the subject) is guided by another (the hypnotist) to respond to suggestions for changes in subjective experience, alterations in perception, sensation, emotion, thought, or behavior” [94]. Hypnosis for pain management usually begins with an induction (e.g., suggestions for focused attention or relaxation) and is followed by suggestions for altering how pain is viewed or experienced. Posthypnotic suggestions are often included and usually involve suggestions about experiences outside a session (e.g., suggestions that pain relief experienced during sessions will last and/or become permanent). Hypnotic treatment for chronic pain typically lasts 4 to 10 sessions; virtually all clinicians encourage patients to practice self-hypnosis for chronic pain outside of treatment sessions [95].

Three recent reviews cover the bulk of published RCTs of hypnotic analgesia [95-96]. In the first study, the authors performed a meta-analysis of 18 studies of laboratory and clinical pain [96]. The average effect size across studies was 0.67 , which lies squarely between a medium (0.50) and large (0.80) effect. This effect size can be interpreted as indicating that the average person treated with hypnosis obtains a greater analgesic response than 75 percent of individuals who are given standard care or no treatment. Patterson and Jensen identified 12 RCTs of hypnotic treatment of chronic pain [95]. In the studies comparing hypnosis with no treatment, standard care, or attention, hypnosis usually resulted in significantly greater reductions in pain than the other treatments. However, when hypnosis was compared with treatments that share many of its characteristics (e.g., PMR), hypnosis was usually not found to be superior to the competing treatments. But, in no case was hypnosis for chronic pain found to be less effective than other treatments, which led the authors to conclude that hypnosis is a viable intervention for chronic pain.

Most recently, Jensen and Patterson identified 19 studies that examined the efficacy of hypnotic analgesia for headache pain (8 studies), mixed chronic pain (3 studies), LBP (2 studies), TMJ pain (2 studies), and cancer-related pain, sickle cell disease pain, fibromyalgia, OA pain, and disability-related pain (1 study each) [90]. As previously found in a review of a subset of these studies, hypnotic treatment produced greater pain reductions relative to standard care and no treatment but had similar effects as PMR and autogenic training [95]. The authors also reported that hypnosis was more effective than medication management (for headache), physical therapy (for fibromyalgia), and education (for TMJ pain). They concluded that “. . . hypnotic treatment for chronic pain results in significant reductions in perceived pain that maintain for at least several months, and possibly longer” [90].

Clinically, hypnosis and hypnotic analgesia has been greatly underutilized. Hypnosis is almost always a benign treatment with very little likelihood of negative side effects. In fact, the "side effects" that occur appear to be overwhelmingly positive and include a greater sense of control over pain, as well as increased overall well-being and decreased tension, stress, and anxiety [97]. To pro- 
vide this treatment, clinicians need to obtain appropriate training in hypnosis and apply this training to reduce their patients' pain and suffering. Consequently, hypnosis is rated as efficacious for treating chronic pain.

\section{Yoga}

Yoga is a Sanskrit term for a group of spiritual practices thought to have originated in India more than 7,000 years ago. Raja Yoga, also known as Astanga Yoga, is the most familiar Western form of yoga. Raja Yoga is described in a codification of yoga philosophy comprising 196 aphorisms, the Yoga Sutras, which were composed by Pantanjali approximately 2,000 years ago. It includes eight stages or limbs: yama (ethical principles), niyama (selfrestraint), asana (postures), pranayama (breath control), pratyahara (withdrawal of the senses), dharana (concentration), dyhana (meditation), and samadhi (liberation). The Hathayoga Pradipika is another primary source for yoga practitioners. It was written in the 15th century by Svatmarama and teaches postures and breathing techniques [98]. The term Hatha Yoga is generally used for the postures and breathing techniques used by yoga practitioners.

Our search identified six RCTs on yoga for chronic pain: LBP (four studies) [99-102], carpal tunnel syndrome (one study) [103], and hand OA (one study) [104]. One LBP study was discarded because it only provided baseline data and no outcomes [102]. The three remaining LBP studies suggested a positive benefit of yoga. The first study found that patients who practiced yoga demonstrated significantly decreased pain and improvements in functional disability compared with an education control group [99]. The effect sizes for functional disability and pain intensity for the yoga group were 2.60 (strong effect) and 0.50 (moderate effect), respectively. The second study reported that yoga, compared with exercise and self-help, yielded significant improvement in functional disability but not symptom "bothersomeness" (including pain) at 12 weeks. Yoga remained superior to self-care but not to exercise at 26 weeks [99]. The third study had inadequate power to detect differences between yoga versus wait-list control but reported trends in favor of the yoga intervention [101]. The single study on carpal tunnel syndrome found that yoga participants demonstrated statistically significant differences in grip strength, pain intensity, and Phalen's sign compared with the control group [103]. Another study reported that patients with hand OA showed statistically significant improvements in pain, joint tenderness, and finger range of motion following yoga [104]. No-treatment controls did not demonstrate significant changes from baseline, although between-group differences were not analyzed.

In summary, the limited studies suggest the potential benefit of yoga therapy and indicate that it is probably efficacious for some cases of LBP and carpal tunnel syndrome, but not enough evidence exists to routinely recommend this intervention. The overall sample demographics of the reviewed studies may not match the usual chronicpain population. The self-referral sample selection likely resulted in a generally healthier and less disabled sample with less unemployment, more education, and relatively lower pain-intensity scores. Further research with a broader, more representative sample is recommended for efficacy determination and appropriate patient selection.

\section{Biofeedback}

Biofeedback is the process of providing real-time information from psychophysiological recordings about the levels at which physiological systems are functioning. Electronic biofeedback devices objectively and noninvasively record tiny changes in physiological functions that cannot be readily detected by other means. Most record from the skin surface. The information recorded by surface sensors is sent to a computer for processing and then displayed on the monitor and/or through speakers. The patient and therapist attend to the display of information and incorporate it into the processes they are attempting to modify. The physiological parameters most often recorded for biofeedback include muscle tension (the surface electromyogram [sEMG]), near-surface blood flow (done by recording skin temperature), heart rate, sweating or galvanic skin response, brain waves (EEG), and respiration.

The available literature on biofeedback for pain control is so extensive that a comprehensive discussion of the efficacy studies is beyond the scope of this review [105-106]. Thus, only the findings for selected pain conditions are briefly discussed. Numerous studies have demonstrated the efficacy of psychophysiological interventions, including biofeedback, for migraine and tensiontype headaches [107-109]. Rains et al. reviewed the meta-

\footnotetext{
*Sherman R, Hermann C. Clinical efficacy of psychophysiological assessments and biofeedback interventions for chronic pain disorders other than head area pain. Unpublished observations; 2006.
} 
analyses and found that biofeedback is highly efficacious for these conditions [110]. Comparative studies have shown that biofeedback is at least as or more effective than standard interventions [111].

Regarding muscle-related orofacial pain, a comprehensive review concluded that biofeedback treatment is effective when the pain is muscle-related rather than originating in the TMJ [112]. Several studies have shown that biofeedback was as or more effective than splint therapy and that the gains were maintained for longer periods [113-114]. A recent review of 12 RCTs concluded that sEMG training with adjunctive CBT is an efficacious treatment for TMJ disorders and that sEMG training as the sole intervention and biofeedback-assisted relaxation training are probably efficacious treatments [115]. For musculoskeletal back pain, reviews indicate that mixed behavioral interventions including biofeedback can be very successful for chronic LBP [116-119]. Reviews of studies on the efficacy of biofeedback for LBP generally concluded that biofeedback helps some patients with muscle-related back pain, with an overall improvement rate of about 65 percent versus 33 percent for placebo and no improvement for no-treatment controls [120].

Additional studies have investigated phantom limb pain and two types have been found to be amenable to biofeedback: burning and cramping pain. Studies have shown that nearly all people with amputations who have cramping pain are helped by sEMG [121]. Unfortunately, about half of the patients with burning pain have not benefited from biofeedback [121]. Many authors do not differentiate between types of phantom limb pain when applying biofeedback but still achieve success [122123]. Regarding fibromyalgia, a series of studies have confirmed that a psychophysiological intervention combining sEMG biofeedback and EEG-driven stimulation effectively treats fibromyalgia [124-126]. These investigators identified diffuse muscular coactivation as a potential source of pain in fibromyalgia and successfully used sEMG biofeedback to reduce the pain in these tender points [124-125].

Biofeedback for pain generally works because it first identifies the patient's individual physiological dysfunctions causing the pain and helps the patient recognize when those dysfunctions are occurring and correct them by watching the display and trying various corrective strategies. For example, most people with chronic muscle-related pain have more difficulty judging the tension in the muscles in the painful area than people without pain [127]. Thus, they tend to keep the muscles too tense for too long and then pain develops. Biofeedback calibrates the sensations coming from the muscles with actual levels of tension.

Side effects of biofeedback therapy for pain are rarely an issue. However, other behavioral therapies commonly used conjointly with biofeedback, such as PMR training, have potentially serious side effects. Side effects may occur when biofeedback is used for treating conditions other than pain. For example, PMR may precipitate panic attacks or hyperventilation when respiratory alterations are induced in some individuals with significant anxiety or asthma and may trigger cardiac events when used with individuals with underlying cardiac problems. One should note that many clinicians who use biofeedback incorporate behavioral techniques such as breathing or relaxation training into their clinical protocols and thus increase the likelihood of side effects.

To conclude, biofeedback is a nonpharmacological intervention that can directly or indirectly help patients cope with their pain. The direct approach, which teaches patients to correct the physiological problem causing their pain, is efficacious for several pain problems. The indirect approach helps patients modulate their pain experience and how pain affects their functioning. Biofeedback used for pain treatment has relatively few known side effects when compared with traditional pain interventions such as medication; it can be the sole pain treatment or an adjunctive treatment combined with other interventions. Sufficient meta-analyses, detailed reviews, assessments by U.S. government-sponsored panels, and high-quality studies with long follow-ups of significant numbers of patients have demonstrated that biofeedback can be efficacious for assessing and treating a variety of disorders characterized by pain.

\section{WHOLE OR PROFESSIONALIZED COMPLEMENTARY AND ALTERNATIVE MEDICINE PRACTICES}

Two systems of whole or professionalized practices will be discussed: homeopathic medicine and acupuncture. These two have been selected because of their popularity and common acceptance by the U.S. public. 


\section{Homeopathy}

Homeopathy is a form of alternative medicine based on the principle of "like cures like." This principle postulates that administering a small amount of a substance that causes illness in a healthy person can also treat the same illness in a sick person. While homeopathy has been used frequently to treat chronic pain, it has seen high levels of controversy and debate because its treatment concepts seem contradictory to the laws of science. Furthermore, controlled trials of homeopathic remedies for painful conditions have produced contradictory results.

In the absence of extant reviews, five studies were found that used homeopathic remedies to treat chronic pain conditions (headaches, arthritis, and back pain) [128-132]. The homeopathic remedies tested were "spiroflor" or homeopathic gel, "rheus-tox," or an individualized menu of homeopathic medicines. Three studies compared a homeopathic remedy with a placebo and two compared homeopathy with active treatments (e.g., anti-inflammatory medication or pain-relieving gel). Studies were relatively short, ranging in length from 1 week to 6 months. While three studies demonstrated greater mean pain reduction from the homeopathic remedy compared with the comparison groups, only one reached statistical significance.

To conclude, relatively few RCTs have investigated homeopathic remedies for pain management. Furthermore, these studies are relatively small (i.e., underpowered to show effect), of short duration, and have methodological shortcomings. Most studies found no significant improvement in pain. Thus, evidence for homeopathic remedies in pain conditions is lacking. Future efforts should focus on larger studies of standardized treatments with more rigorous methodology.

\section{Acupuncture}

Acupuncture involves penetration of the skin by thin, solid, metallic needles that are stimulated either manually or electrically. It is one of several TCM therapies that have been used for thousands of years in the treatment of a variety of health problems. Today, acupuncture therapy is commonly used for pain control throughout the world, although the putative mechanisms are complex and unclear. Practitioners apply many different models and approaches in acupuncture practice, ranging from the metaphysical paradigm used by traditionally trained practitioners to the strictly neurophysiologic approach more commonly used by physicians treating patients exclusively for pain.

TCM is a complete system of healthcare delivery. Therefore, a discussion of the efficacy of acupuncture must be prefaced with an understanding of the problems that occur when researchers attempt to evaluate treatments from one diagnostic paradigm (i.e., TCM) to diagnoses made with a different paradigm (i.e., allopathic medicine). Many studies have evaluated the use of acupuncture for symptoms that are either side effects of biomedical treatment (e.g., pain, fatigue) or related to a specific disease process (e.g., OA). TCM syndromes, however, are not equivalent to either of these side effect types as defined by a biomedical model. One must therefore use caution when interpreting results from studies that apply a TCM treatment to anything other than a TCM-related diagnosis or syndrome.

TCM syndromes, such as yin/yang deficiencies or qi stagnation, are unique symptom complexes that result from imbalances between the body's various functional systems. Since TCM is based on functional relationships and TCM diagnoses involve syndromes not diseases, no one-to-one correlation of signs and symptoms between TCM diagnoses and biomedical diseases exists. The diagnostic symptom complexes used in TCM differ from an allopathic model, and treatment is given according to individual patterns of system imbalances. As a result, certain aspects of human physiological functional relationships are emphasized that are not directly addressed by a biomedical paradigm. Results from RCTs of acupuncture will continue to be equivocal and show little more than a comparison of "apples to oranges" until studies are designed that recognize and include evaluation of the underlying TCM syndrome.

Since the 1970s, hundreds of clinical trials evaluating the efficacy of acupuncture for various conditions have been conducted. Many, however, were poorly designed and few included treatment protocols as applied in actual clinical practice. Nevertheless, in some areas related to pain management, reviews provide sufficient evidence of efficacy to draw clear conclusions. For example, acupuncture is generally agreed to effectively treat postoperative dental pain, as well as postoperative and chemotherapyrelated nausea and vomiting [133]. More recently, substantial evidence indicates that acupuncture is also effective in treating chronic LBP [134-135] and support for the efficacy of acupuncture for premenstrual syndrome has been published in China [136]. One reviewer found that 
results from studies on efficacy are considered (1) positive by some and difficult to interpret by others for the treatment of migraine and TMJ disorders; (2) promising for fibromyalgia, knee OA, and tennis elbow, although additional research is needed; and (3) inconclusive or difficult to interpret for neck pain [137].

To summarize, acupuncture has traditionally been used as adjunctive therapy for a variety of conditions. Although hard data from modern research methods are sparse regarding the synergistic effects of acupuncture combined with other therapies, a great deal of literature has evaluated its safety [138-141] and efficacy for certain conditions. For patients at risk for adverse reactions to pharmaceutical therapy or for any patient who prefers acupuncture over drugs, acupuncture should be used as an adjunct in pain management. Its relatively low cost, low risk for serious adverse events, and ease of application make it particularly suitable in patients for whom standard treatment methods have failed. More specific recommendations for integrating acupuncture into clinical care will become available as our understanding of its putative mechanisms evolves. In the meantime, acupuncture can be considered probably efficacious for treating LBP and possibly efficacious for treating premenstrual syndrome.

\section{CONCLUSIONS ON EFFICACY OF COMPLEMENTARY AND ALTERNATIVE MEDICINE MODALITIES FOR CHRONIC PAIN MANAGEMENT}

This review has evaluated existing evidence for the efficacy of various CAM modalities for treatment of chronic pain based on the APA guidelines (Figure) [5]. A summary of the evidence for the efficacy of each selected CAM modality is provided in Table 1, while ratings for the efficacy of each CAM modality are provided in Table 2.

Evidentiary data must be used to (1) guide clinicians' consideration of the risk and burden-to-benefit ratios of particular CAM therapies, (2) afford knowledge that can be provided to patients for genuine informed consent to treatment, and (3) facilitate potential CAM integration into the mainstream model of healthcare [142]. Yet several challenges to the study of CAM therapies exist, such that the basic question is not simply which CAM interventions should be studied but rather how they should be studied. Therefore, Giordano et al. recently proposed the use of hierarchical research approaches that use mixed methods (i.e., quantitative as well as qualitative techniques) together with forms of RCT, adapted to best meet the contextual factors inherent to the use and "realworld" application(s) of various CAM therapies [143].

Several methodological limitations were found in the trials we reviewed. Among the most serious of these were (1) small sample sizes, (2) lack of follow-up data, (3) inadequate blinding of assessors, (4) paucity of trials that included comparison conditions that controlled for nonspecific effects (e.g., therapist time/attention, physical contact), (5) lack of replication studies in independent research groups, and (6) for certain nonpharmacological approaches (e.g., massage, TT), little information on the extent to which procedures were standardized. Future trials should remedy these limitations and provide a more rigorous evidence base for the use of CAM in pain management.

\section{RECOMMENDATIONS TO PRACTITIONERS}

Available evidence indicates that the public has been using CAM modalities for many years and will likely continue to do so with or without the blessing of pain or other clinical practitioners. Therefore, pain practitioners must become more familiar with the efficacy of CAM modalities and consider incorporating those CAM treatments with evidence supporting their efficacy into daily practice whenever indicated and/or appropriate.

This review indicates that CAM modalities, as a group, have a mixed efficacy track record, with some approaches having more evidence to support their efficacy than others (Table 1). For example, although not everyone responds to these treatments and the immediate efficacy of the treatments is not always maintained, support for the efficacy of hypnosis, biofeedback, and massage therapies for LBP and shoulder pain is greater than that for numerous control conditions and, in some cases, other treatments. The efficacy of PEMF has been demonstrated for migraine headaches and OA of the knee and cervical spine but no other pain condition. CES, massage therapies for neck and other pain conditions, SMT, meditation, and yoga appear to be promising treatments, but more research is needed to replicate preliminary findings. The CAM treatments that showed mixed results include herbal and dietary interventions (perhaps because these represent hundreds of interventions, so mixed results are 
expected), TT, craniosacral therapy, Reiki, qigong, and homeopathy. However, even these interventions might help a subgroup of patients.

Acupuncture appears to belong in its own category. While multiple meta-analyses and clinical trials support the efficacy of acupuncture as an analgesia and treatment for many medical conditions, relatively few studies have focused on chronic pain conditions. As discussed in the acupuncture section, the lack of studies on chronic pain

Table 1.

Summary of evidence for efficacy of selected complementary and alternative medicine (CAM) modalities.

\begin{tabular}{|c|c|c|c|c|c|}
\hline Modality & $\begin{array}{l}\text { Cochrane } \\
\text { Review? }\end{array}$ & Other Review? & $\begin{array}{c}\text { Meta- } \\
\text { Analysis? }\end{array}$ & $\begin{array}{c}\text { Randomized } \\
\text { Controlled Trial? }\end{array}$ & $\begin{array}{l}\text { No Control, But Well- } \\
\text { Designed Studies? }\end{array}$ \\
\hline \multicolumn{6}{|l|}{ Biologically Based Medicine } \\
\hline $\begin{array}{l}\text { Herbal Remedies/Dietary } \\
\text { Supplements }\end{array}$ & Yes & Yes & No & Yes (91) & Yes $(>100)$ \\
\hline \multicolumn{6}{|l|}{ Energy Medicine } \\
\hline Pulsed Electromagnetic Fields & No & No & No & Yes (3) & Yes \\
\hline Therapeutic Touch & No & Yes & No & Yes (6) & No \\
\hline Reiki & No & No & No & Yes (1) & Yes (2) \\
\hline Qigong & No & No & No & Yes (4) & Probably \\
\hline $\begin{array}{l}\text { Cranial Electrotherapy } \\
\text { Stimulation }\end{array}$ & No & Yes & No & Yes (4) & Yes (1) \\
\hline \multicolumn{6}{|l|}{ Mind-Body Medicine } \\
\hline Meditation & No & Yes & Yes & Yes (10) & Yes \\
\hline Hypnosis & No & Yes (several) & Yes & Yes (19) & Yes (9) \\
\hline Yoga & No & No & No & Yes (5) & Yes \\
\hline Biofeedback & No & Yes & Yes & Yes (large number) & Yes (large number) \\
\hline \multicolumn{6}{|c|}{ Manipulative Body-Based Medicine } \\
\hline Chiropractic & Yes & Yes & Yes & Yes (47) & Yes (15) \\
\hline Massage Therapy & Yes & Yes & Yes & Yes $(>50)$ & Not Sure \\
\hline \multicolumn{6}{|l|}{ Whole or Professionalized CAM } \\
\hline Homeopathy & No & No & No & Yes (5) & Not Sure \\
\hline Acupuncture & Yes & Yes & Yes & $\begin{array}{c}\text { Yes ( }>80 \text { for chronic } \\
\text { low back pain) }\end{array}$ & Yes (large number) \\
\hline
\end{tabular}

may be partially due to acupuncture being originally an integral part of TCM, which conceptualizes health and illness from a very different paradigm. In short, the efficacy of acupuncture as analgesia is not disputed, but studies of its efficacy in treating chronic-pain diagnoses as defined by Western nomenclature have mixed results.

In addition to efficacy, other issues are relevant to practitioners making decisions about using or incorporating CAM modalities into their pain practice. These issues include additional time and energy investments, the need for specially trained personnel to administer the modalities, known or potential side effects, safety in combining CAM and other modalities, likely acceptance by clients and the public (and hence the issue of long-term adherence), and ease of incorporation into traditional painmanagement practices.

\section{Additional Requirements}

Biofeedback requires equipment and specialized training. Many treatments, including acupuncture, homeopathy, massage, and chiropractic care, require a licensed practitioner. Also, some CAM modalities may produce concrete results in just a few sessions for some patients (e.g., CES, hypnosis, biofeedback), while others may require more time and effort (e.g., yoga, meditation). In general, CAM modalities as a group take longer than traditional medical pain interventions to achieve results.

\section{Side and Toxic Effects}

Another important issue is that, compared with traditional pain interventions, CAM modalities as a group have fewer known, documented side and toxic effects. For example, the "side effects" of training in self-hypnosis 
for chronic pain are overwhelmingly positive [97]. This fact may explain, at least in part, the popularity of CAM modalities relative to traditional medical interventions, which tend to be invasive and undermine patient selfefficacy and control.

\section{Table 2.}

Efficacy of selected complementary and alternative medicine (CAM) interventions for chronic pain. Efficacy levels based on American Psychological Association guidelines (see Figure).

\begin{tabular}{ccc}
\hline Modality & Level of Efficacy & Explanation \\
\hline Biologically Based Medicine &
\end{tabular}

Herbal Remedies/Dietary Supplements

\section{Energy Medicine}

Pulsed Electromagnetic Fields

Therapeutic Touch

Reiki

Qigong

Cranial Electrotherapy Stimulation

\section{Mind-Body Medicine}

Meditation

Hypnosis

Yoga

Biofeedback

\section{Manipulative Body-Based Medicine}

Chiropractic

$2-3$

2

\section{Combining Complementary and Alternative Medicine and Other Modalities}

Another issue that clinicians should consider is that some CAM modalities can be combined safely with each
$2-3$

(1)

Rar

Level 3: Glucosamine/chondroitin sulfate for arthritis conditions. Level 2: Other dietary supplements. Studies show mixed findings; pain conditions studied were extremely diverse.

Level 3: Migraines \& knee osteoarthritis.

Level 2: Osteoarthritis of cervical spine.

Promising for chronic musculoskeletal pain \& pain related to knee osteoarthritis; less support for fibromyalgia or degenerative arthritis. Studies have several methodological weaknesses. Only 1 controlled study showed modest reductions in cancer pain. Level 3: Mixed chronic pain; findings need replication in independent research group.

Level 2: Complex Regional Pain Syndrome Type I.

Level 2: Dental anesthesia, spinal cord injury, \& fibromyalgia pain.

Meditation demonstrated improvement from baseline in numerous studies \& reviews, including randomized controlled trials. Samples were small \& restricted.

Hypnotic analgesia treatments are more effective than no treatment. However, hypnosis is not more effective than other treatments that include hypnoticlike suggestions, e.g., relaxation training.

Randomized controlled trials showed benefit for low back pain. Studies in carpal tunnel \& osteoarthritis used withingroup comparisons. All samples predominately female.

Level 4: Migraine, tension headaches, \& muscle-related orofacial pain.

Level 3: Stress \& muscle tension-related incontinence, cramping \& burning phantom pain, irritable bowel syndrome, Reynaud's, posture-related pain, stress-induced chest pain.

Level 2: Premenstrual syndrome \& dysmenorrhea, pain from spastic muscles \& muscle spasms, pelvic-floor pain, carpel tunnel syndrome, myofascial/trigger point-related pain, fibromyalgia.

3 Spinal manipulation therapy had beneficial effects in multiple studies. However, higher quality studies needed before concluding that it is more efficacious that placebo, routine medical care, or exercise. 
Table 2. (Continued)

Efficacy of selected complementary and alternative medicine (CAM) interventions for chronic pain. Efficacy levels based on American Psychological Association guidelines (see Figure).

Massage Therapy $\quad 2-4 \quad$ Different ratings designated depending on pain condition because quality of studies varied widely.

Level 4: Low back pain.

Level 3: Shoulder pain.

Level 2: Fibromyalgia, neck pain, headache, carpel tunnel syndrome.

\begin{tabular}{lcl}
\hline \multicolumn{1}{c}{ Modality } & Level of Efficacy & \multicolumn{1}{c}{ Explanation } \\
\hline $\begin{array}{l}\text { Whole or Professionalized CAM Practices } \\
\text { Homeopathy }\end{array}$ & 2 & $\begin{array}{l}\text { Only } 1 \text { in } 5 \text { studies found significant pain decreases with } \\
\text { homeopathic remedies compared with placebo. This } 1 \text { study } \\
\text { was lower in quality relative to other studies. } \\
\text { Acupuncture effectively treats dental, chemotherapy-related, \& } \\
\text { chronic low-back pain; probably effective for premenstrual } \\
\text { scupuncture }\end{array}$ \\
\hline \hline
\end{tabular}

other and with traditional pain interventions to produce additive or synergistic effects. For example, CES can be administered easily with self-hypnosis or biofeedback training or with psychotherapy. In this way, any potential benefits of the individual treatments can combine for maximum pain relief for the patient.

Interest in combined traditional medical treatments for maximum pain relief is increasing, but no reason exists that more established CAM modalities should not at least be considered during development of multimodal treatment plans [137]. Additional research must examine the use of individual CAM therapies with other CAM approaches and with traditional interventions in terms of safety and synergistic effects. Recently, some concerns have arisen regarding the combined use of medication and herbal preparations [144-145]. Some herbal preparations should be avoided completely because of their very rapid, irreversible actions [144-145].

\section{Acceptance, Adherence, and Ease of Incorporation}

The popularity of CAM therapies for chronic pain has been partially fueled by the current lack of efficacious treatments for chronic pain. However, after the initial desperation for relief and the curiosity and novelty of new treatments have worn off, long-term compliance may emerge as a potential road block to successful positive outcome. Little data indicate which CAM therapies would more likely incur acceptance and compliance and which would not. In the absence of empirical data, one might assume that those CAM modalities that resonate with current ideas of medical treatments would be more readily accepted. Thus, herbal and dietary supplements may have an advantage in adherence since the public has become acculturated to the idea of taking medications to get and stay well. Treatments that use sophisticated equipment, such as biofeedback, CES, PEMF, and acupuncture (perhaps only the electrical stimulation activity, not as part of TCM) may also have an advantage. The idea of "massaging" away tension and pain and the use of chiropractic manipulations for reducing pain are ingrained in the human psyche. Hypnosis for "mind control" might be more effective for people who believe that the brain modulates pain. Yoga, meditation, healing touch, and qigong may have foreign connotations and would more likely appeal only to a subsample of the general public. Ease of incorporation into pain practices is likely influenced by the level of acceptance of and subsequent compliance with the CAM modalities.

\section{Other Advantages of Complementary and Alternative Medicine Use}

The use of CAM may lead to greater acceptance of traditional interventions. A case in point is the use of CES for increased acceptance of psychological interventions such as CBT. Tan et al. showed that the use of CES could lead veterans to engage in psychological therapy or MBT because they perceived CES to be a "real" physical treatment that could rapidly reduce pain and credibly 
treat "real" pain [146]. Once engaged, the veterans became more amenable to participating and benefiting from other MBTs or psychological therapies.

Overall, this review indicates that some CAM modalities provide significant relief for individuals with chronic pain and that, for some individuals, this relief is maintained over time. While more research is needed to specify the mechanisms of different CAM treatments, enough evidence supports offering at least a subset (in particular, biofeedback and self-hypnosis training) to patients who express interest. As more is learned about the efficacy of CAM approaches and as those approaches with established efficacy are provided more consistently to individuals with chronic pain, we can anticipate greater reductions in the disability and suffering associated with chronic pain conditions.

\section{MECHANISM OF ACTION}

Giordano's recent review of pain modulatory mechanisms described the involvement of several systems, including, but not limited to, intraspinal-segmental pain modulation, bulbospinal pain modulation, centrifugal pain modulation involving midbrain and descending inhibitory controls, opioid and nonopioid hypothalamicpituitary analgesia, and corticolimbic inhibitory processing [147]. Literature supports the concept that particular CAM therapies may engage one or more of these systems to evoke analgesia. Clearly, a detailed discussion of the putative mechanisms subserving each CAM approach addressed is beyond the scope of this article. As well, we must note that each system represents part of a hierarchy of neural pathways that function as nonlinear, parallel, and serial processing networks. Thus, one must understand that pain modulation may involve both temporal and anatomical reorientation/redirection of these networks, rather than simply a change in activity at a single neuroanatomical site or within a unitary tract or pathway [148]. A brief summary follows of the known or purported mechanism of action for the CAM modalities covered in this review. Similar to traditional therapies, the actual mechanisms responsible for the pain-modulating effects are putative and ongoing methodologically progressive but no less rigorous research is required for a fuller definition of which anatomical pathways and chemical systems are involved and how these substrates actually change the mental state (i.e., sensation, perception, and/or cognition) of pain $[143,149-150]$.

\section{Biologically Based Medicine: Supplements}

Glucosamine and chondroitin sulfate are the most widely used dietary supplements for pain secondary to OA. The supplements' mechanisms of action in relieving arthritic pain and repairing cartilage are still speculative [151]. Setnikar and Rovati demonstrated that after oral administration, glucosamine sulfate is bioavailable and reaches the articular cartilage, which is the purported site of action [152]. Glucosamine sulfate is involved in glycoprotein metabolism and is preferentially incorporated by chondrocytes into the components of glycosaminoglycan chains of intact cartilage [151,153].

Additional evidence suggests that glucosamine sulfate reverses some of the negative inflammatory effects of interleukin-1 on cartilage metabolism, which possibly explains the long-term benefits on joint structural changes [153]. Furthermore, early effects observed during shorter treatment periods with glucosamine sulfate may be explained by the anti-inflammatory effects mediated by suppressing superoxide radical generation, inhibiting nitric oxide synthesis, or selectively inhibiting the cyclooxygenase-2 pathway [153].

Like glucosamine sulfate, chondroitin sulfate is derived from animal products and its mechanism of action remains uncertain. Chondroitin sulfate is a glycosaminoglycan found in the proteoglycans of articular cartilage. It has demonstrated anti-inflammatory activities, anti-arthritic effects, and favorable effects on cartilage metabolism in vitro [154]. Animal studies have shown that both parenterally and orally administered chondroitin sulfate are incorporated into cartilage and articular tissue. Orally administered chondroitin sulfate increases hyaluronic acid and synovial fluid viscosity, which possibly explains its favorable effect on joint pain and mobility [155].

In addition to glucosamine and chondroitin sulfate, numerous other dietary supplements and herbal substances have been used for treating painful conditions. Some of the most commonly used supplements include fatty acids, fish oils, aromatic oils, and cannabis derivatives. Because of the paucity of high-quality research involving these supplements, drawing conclusions about their mechanisms of action is difficult. More methodologically rigorous studies and greater standardization of 
supplements and herbal medications are needed before their mechanisms of action can be accurately elucidated.

\section{Energy Medicine}

\section{Pulsed Electromagnetic Field Therapy}

Relatively high-power PEMF generators have been shown to increase blood flow in the areas exposed to the fields [156], which, at least in the case of rabbits, can last for up to 3 years [157]. Increased peripheral blood flow commonly results in reduced migraine activity through yet undiscovered mechanisms [158].

\section{Cranial Electrotherapy Stimulation}

Some evidence indicates changes in neurotransmitters, including serotonin and norepinephrine, as a result of CES treatment. Giordano provides a further discussion of the putative mechanism of action of CES [159].

\section{Therapeutic Touch}

The purported mechanism of action for TT is based on the assumption that we live in a pandimensional, unitary world wherein energy fields are the fundamental units of humans and their environment, and linear time and separation of human and environmental fields do not exist [160]. Pain and other symptoms occur when energy is imbalanced, and therapists are purported to identify and correct energy imbalances in the patient's body to affect the pain experience. TT is viewed as a purposeful patterning of therapist-environmental/patient-environmental energy-field mutual processes that promotes maximum patient healing and well-being [161].

\section{Reiki}

Two main mechanisms of action for Reiki have been proposed: gate theory (see the subsequent discussion of massage therapy) and coverage of the main meridians treated in acupuncture [38].

\section{Qigong}

Qigong literally means "working on the qi or "vital energy' in the body." To better understand the purported mechanism of action, one has to accept the basic tenet of TCM that pain and other symptoms are related to the quality, flow, and imbalance of qi in the human body [41]. Qigong may involve not only the patient cultivating his or her qi to achieve optimal health in mind and body but also qigong healers or practitioners directing or emit- ting their qi energy to help patients clear qi imbalances or blockages or to move bad qi out of the body for pain relief [43]. Further specification of the mechanism of action is inexplicable within the Western medical model.

\section{Manipulative and Body-Based Medicine}

\section{Chiropractic Manipulation}

Chiropractors use hands-on therapy called manipulation as their core clinical procedure. Chiropractic manipulation is a form of spinal manipulation. The term SMT is often reserved for thrust manipulation: a passive movement of a joint(s) and its components (i.e., ligaments, tendons, and cartilage) beyond their normal physiological range. Manipulation involves low-amplitude and highvelocity maneuvers [162]. While both mobilization and manipulation aim to reduce pain and increase joint range of motion, the techniques used vary significantly. This variability has led to uncertainty about the underlying mechanism of action.

Numerous hypotheses have been proposed to explain the efficacy of SMT [163]. The research to date suggests that SMT has three primary anatomic effects: (1) separation of facet joint surfaces, (2) relaxation of the paraspinal muscles, and (3) lowering of intradiscal pressure. Most of these changes are short-lived, and an explanation of the long-term therapeutic effects has not yet been established. Further research should delineate the biomechanical consequences of specific manipulative techniques on vertebral motion.

\section{Massage Therapy}

The main mechanistic theories for the analgesic effects of massage are gate theory [164], the serotonin hypothesis [165], and the restorative-sleep hypothesis [27]. Gate theory proposes that because pressure receptors are longer and more myelinated than pain fibers, pressure signals from massage are transmitted faster and close the gate to pain signals. The serotonin hypothesis purports that massage increases serotonin levels, which is thought to modulate the pain-control system. The restorative-sleep hypothesis maintains that because substance $P$, a neurotransmitter associated with pain, is released in the absence of deep sleep, promotion of restorative sleep by massage reduces substance $P$ and pain [64].

\section{Craniosacral Therapy}

Proponents of craniosacral therapy maintain that movement restrictions in the cranial structures of the skull 
adversely affect rhythmic impulses conveyed through the cerebral spinal fluid from the cranium to the sacrum [71]. Craniosacral therapists propose that gentle pressure on external areas, including the head and back, enhance the motion of tissue and cerebral spinal fluid and thus restore the flexibility of the autonomic response, which leads to reduced symptoms, including pain.

\section{Mind-Body Medicine}

\section{Meditation}

Meditation effects are thought to be based in changes in awareness of pain behaviors. These changes in awareness create flexible attention that allows individuals to observe their habitual emotional and cognitive reactions to pain and then change them to more adaptive reactions [80-81]. Related to this shift in cognitive and emotional processing away from a habitual alarm state are increased self-efficacy, improved coping capacities, and general attenuation of stress [83]. Another potential mechanism is the relaxation that often accompanies meditation and is often a goal of concentrative meditation techniques [166]. Meditation may also share a mechanism thought to be common to several MBTs: the release of nitric oxide that stimulates vasodilatation, anti-inflammatory, and morphinergic and/or endocannabinoid activity [167-168].

\section{Hypnosis}

No clear mechanism for hypnotic analgesia has been identified, although evidence exists that brain activity in the sensory cortex and limbic system are differentially affected as a function of the type of suggestion given (i.e., decreased pain sensations vs decreased bothersomeness of pain) [169-171] and that hypnotic-analgesia suggestions can alter sensory information processing at the level of the spinal cord [172-173].

\section{Yoga}

No specific mechanism of action for yoga has been established by existing studies. In the yogic tradition, benefits are thought to be related to the quieting of the negative impulses of the mind, which improves the individual's functioning of the organ and musculoskeletal systems and increases his or her ability to use breath energy or prana [98]. General mechanisms of action associated with yoga could include physical effects, such as improved flexibility and strength and reduced postural guarding and other habitual physical behaviors associ- ated with chronic pain. Mental effects could include increased mental focus, improved body awareness, and changed beliefs about physical ability and pain. General stress reduction through activity and relaxation exercises is also a potential mechanism.

\section{Biofeedback}

The mechanism of action for biofeedback in pain management has not been fully established. However, evidence is increasing that for chronic muscle or myofascial pain syndrome, pain modulation with biofeedback is achieved via decatastrophizing and learning lowered arousal techniques that prevent the maintenance of sympathetic pathways to trigger points $[112,174]$. For pain conditions such as fibromyalgia, phantom, and other centrally mediated pain, biofeedback may counter the effect of central sensitization through decreasing sympathetic overload, parasympathetic withdrawal, and stress hormones. Some evidence also exists that changing improper muscle contraction and blood flow patterns directly affect pain caused by these problems $[105,127]$.

\section{Whole or Professionalized Complementary and Alternative Medicine Practices}

\section{Homeopathy}

A key premise of homeopathy is that each person has innate energy called a "vital force" or a self-healing response. When a person's energy is disrupted or imbalanced, health problems such as chronic pain may develop. Therefore, the overriding goal of homeopathic practice is the recommendation of remedies that stimulate the body's own healing responses. The primary mechanism of homeopathy is based on the law of "similars" or the "like cures like" principle. This theory proclaims that if a large amount of a certain substance can cause specific symptoms in a healthy person, smaller amounts of that same substance can treat symptoms in an ill person [175]. Thus, the practitioner of homeopathy would attempt to stimulate the healing responses by providing a smaller amount of the same substance that caused the symptoms. Unfortunately, no published empirical evidence supports this theory [176].

\section{Acupuncture}

Although many studies have documented the efficacy of acupuncture for pain and other medical conditions, understanding how it works within a Western medical 
paradigm remains challenging. Like qigong, acupuncture originated in TCM. In TCM, regulation of qi is the major source of health problems and illness and acupuncture purportedly treats pain and other conditions by improving the quality, balance, and flow of qi. In Western medical nomenclature, the proposed mechanisms involve regulation of the nervous system, stimulation of the immune system, and alteration of the brain chemistry and cause the release of various neurotransmitters and hormones. Thus, acupuncture affects parts of the central nervous system related to sensation and involuntary body functions, such as immune reactions and processes that regulate a person's blood pressure, blood flow, and body temperature [177-178].

\section{CONCLUSIONS}

We reviewed the published research on commonly used CAM treatments for chronic pain. Our findings show that CAM therapies, as a group, have a mixed track record for efficacy. Not only do the different CAM modalities show different levels of efficacy but one modality may work for one pain condition but not others. The CAM modalities with the best track records for pain management are biofeedback, hypnosis, and massage (particularly for low back and shoulder pain). In selecting a CAM modality either as an alternative or complement to traditional pain interventions, such as medication, practitioners must weigh the pros and cons of the modality and tailor the interventions to the needs of the chronic pain patient. In addition to efficacy, other issues that practitioners must consider when making decisions about CAM use include additional time and energy investments, the need for specialized trained personnel to administer the modalities in question, known side effects or potential toxic effects, safety in combining CAM and other modalities, likely acceptance by clients and the public (and hence issues of long-term compliance), and ease of incorporation into traditional pain management practices.

\section{ACKNOWLEDGMENTS}

We wish to acknowledge the financial support provided by the National Headache Foundation, the U.S. Army Medical Command's Department of Clinical Inves- tigation, the National Institutes of Health, the National Institute of Child Health and Human Development, the National Center for Medical Rehabilitation Research, the National Institute on Drug Abuse, the National Institute of Mental Health, and the Department of Veterans Affairs Health Services Research and Development Service.

Contributions to this article are reflected in the order of authorship as follows: Dr. Tan, Dr. Tsao, Dr. Craine, Dr. Bair; remaining authors shown in alphabetical order.

This material was based on work supported in part by the National Headache Foundation (Dr. Sherman), the U.S. Army Medical Command's Department of Clinical Investigation (Dr. Sherman), the National Institutes of Health (grant R01 GM42725-09A1, Drs. Patterson and Jensen), the National Institute of Child Health and Human Development, the National Center for Medical Rehabilitation Research (grant P01 HD33988, Drs. Patterson and Jensen), the National Institute on Drug Abuse (grant 5R03 DA17026-2, Dr. Tsao), the National Institute of Mental Health (grant 5R01 MH063779-03, Dr. Tsao), and a Department of Veterans Affairs Health Services Research and Development Career Development Award (Dr. Bair).

The authors have declared that no competing interests exist.

\section{REFERENCES}

1. Eisenberg DM, Kessler RC, Foster C, Norlock FE, Calkins DR, Delbanco TL. Unconventional medicine in the United States. Prevalence, costs, and patterns of use. N Engl J Med. 1993;328(4):246-52. [PMID: 8418405$]$

2. Barnes PM, Powell-Griner E, McFann K, Nahin RL. Complementary and alternative medicine use among adults: United States, 2002. Adv Data. 2004;(343)1-19. [PMID: 15188733]

3. Eisenberg DM, Davis RB, Ettner SL, Appel S, Wilkey S, Van Rompay M, Kessler RC. Trends in alternative medicine use in the United States, 1990-1997: Results of a follow-up national survey. JAMA. 1998;280(18):1569-75. [PMID: 9820257]

4. Center for Medicare and Medicaid Services [homepage on the Internet]. Washington (DC): U.S. Department of Health and Human Services; [updated 2007 Jan 18; cited 2007 Mar 12]. 1997 National Health Expenditure Data; [about 7 screens]. Available from: http://www.cms.hhs.gov/ statistics/nhe/

5. Chambless DL, Baker MJ, Baucaom DH, Beutler LE, Calhoun KS, Crits-Cristoph P, Daiuto A, DeRubeis R, Det- 
weiler J, Haaga DAF, Johnson SB, McCurry S, Mueser KT, Pope KT, Sanderson WC, Shoham V, Stickle T, Williams DA, Woody SR. Update on empirically validated therapies II. Clin Psychol. 1998;51(1):3-16.

6. Chambless DL, Hollon SD. Defining empirically supported therapies. J Consult Clin Psychol. 1998;66(1):7-18. [PMID: 9489259]

7. Gagnier JJ, van Tulder M, Berman B, Bombardier C. Herbal medicine for low back pain. Cochrane Database Syst Rev. 2006;(2):CD004504. [PMID: 16625605]

8. Clegg DO, Reda DJ, Harris CL, Klein MA, O’Dell JR, Hooper MM, Bradley JD, Bingham CO 3rd, Weisman MH, Jackson CG, Lane NE, Cush JJ, Moreland LW, Schumacher HR Jr, Oddis CV, Wolfe F, Molitor JA, Yocum DE, Schnitzer TJ, Furst DE, Sawitzke AD, Shi H, Brandt KD, Moskowitz RW, Williams HJ. Glucosamine, chondroitin sulfate, and the two in combination for painful knee osteoarthritis. N Engl J Med. 2006;354(8):795-808. [PMID: 16495392]

9. Fini M, Giavaresi G, Carpi A, Nicolini A, Setti S, Giardino R. Effects of pulsed electromagnetic fields on articular hyaline cartilage: Review of experimental and clinical studies. Biomed Pharmacother. 2005;59(7):388-94. [PMID: 16084055]

10. Hulme J, Robinson V, DeBie R, Wells G, Judd M, Tugwell P. Electromagnetic fields for the treatment of osteoarthritis. Cochrane Database Syst Rev. 2002;(1): CD003523. [PMID: 11869668]

11. Pelka RB, Jaenicke C, Gruenwald J. Impulse magneticfield therapy for migraine and other headaches: A doubleblind, placebo-controlled study. Adv Ther. 2001;18(3): 101-9. [PMID: 11571822]

12. Lappin MS. Non-invasive pulsed electromagnetic therapy for migraine and multiple sclerosis. In: Rosch PJ, Markov $\mathrm{M}$, editors. Clinical applications of bioelectromagnetic medicine. New York (NY): Marcel Dekker Publishing; 2004. p. 277-91.

13. Sherman RA, Robson L, Marden LA. Initial exploration of pulsing electromagnetic fields for treatment of migraine. Headache. 1998;38(3):208-13. [PMID: 9563212]

14. Sherman RA, Acosta NM, Robson L. Treatment of migraine with pulsing electromagnetic fields: a doubleblind, placebo-controlled study. Headache. 1999;39(8): 567-75. [PMID: 11279973]

15. Oschman JL. Recent developments in bioelectromagnetic medicine. In: Rosch PJ, Markov M, editors. Bioelectromagnetic medicine. New York: Marcel Dekker Publishing; 2004.

16. Thamsborg G, Florescu A, Oturai P, Fallentin E, Tritsaris $\mathrm{K}$, Dissing S. Treatment of knee osteoarthritis with pulsed electromagnetic fields: A randomized, double-blind, pla- cebo-controlled study. Osteoarthritis Cartilage. 2005;13(7): 575-81. [PMID: 15979009]

17. Nicolakis P, Kollmitzer J, Crevenna R, Bittner C, Erdogmus CB, Nicolakis J. Pulsed magnetic field therapy for osteoarthritis of the knee-A double-blind sham-controlled trial. Wien Klin Wochenschr. 2002;114(15-16):678-84. [PMID: 12602111]

18. Trock DH, Bollet AJ, Markoll R. The effect of pulsed electromagnetic fields in the treatment of osteoarthritis of the knee and cervical spine. Report of randomized, double blind, placebo controlled trials. J Rheumatol. 1994;21(10): 1903-11. [PMID: 7837158$]$

19. Trock DH, Bollet AJ, Dyer RH Jr, Fielding LP, Miner WK, Markoll R. A double-blind trial of the clinical effects of pulsed electromagnetic fields in osteoarthritis. J Rheumatol. 1993;20(3):456-60. [PMID: 8478852]

20. Sutbeyaz ST, Sezer N, Koseoglu BF. The effect of pulsed electromagnetic fields in the treatment of cervical osteoarthritis: A randomized, double-blind, sham-controlled trial. Rheumatol Int. 2006;26(4):320-24. [PMID: 15986086]

21. Peroz I, Chun YH, Karageorgi G, Schwerin C, Bernhardt O, Roulet JF, Freesmeyer WB, Meyer G, Lange KP. A multicenter clinical trial on the use of pulsed electromagnetic fields in the treatment of temporomandibular disorders. J Prosthet Dent. 2004;91(2):180-87. [PMID: 14970765$]$

22. Clark MS, Silverstone LM, Lindenmuth J, Hicks MJ, Averbach RE, Kleier DJ, Stoller NH. An evaluation of the clinical analgesia/anesthesia efficacy on acute pain using the high frequency neural modulator in various dental settings. Oral Surg Oral Med Oral Pathol. 1987;63(4):501-5. [PMID: 3554095]

23. Heffernan M. The effect of variable microcurrents on EEG spectrum and pain control. Can J Clin Med. 1997; 4:4-11.

24. Naveau S, Barritault L, Zourabichvili O, Champagne C, Prieur G, Limoge A, Poynard T, Chaput JC. Analgesic effect of transcutaneous cranial electrostimulation in patients treated by Nd:YAG laser for cancer of the rectum. A double-blind randomized trial [French]. Gastroenterol Clin Biol. 1992;16(1):8-11. [PMID: 1537485$]$

25. Lichtbroun AS, Raicer MM, Smith RB. The treatment of fibromyalgia with cranial electrotherapy stimulation. J Clin Rheumatol. 2001;7(2):72-78. [PMID: 17039098$]$

26. Tan G, Rintala DH, Thornby JI, Yang J, Wade W, Vasilev C. Using cranial electrotherapy stimulation to treat pain associated with spinal cord injury. J Rehabil Res Dev. 2006;43(4):461-74. [PMID: 17123186]

27. Ireland M, Olson M. Massage therapy and therapeutic touch in children: State of the science. Altern Ther Health Med. 2000;6(5):54-63. [PMID: 10979162] 
28. Kemper KJ, Kelly EA. Treating children with therapeutic and healing touch. Pediatr Ann. 2004;33(4):248-52.

[PMID: 15101231]

29. Peters RM. The effectiveness of therapeutic touch: A meta-analytic review. Nurs Sci Q. 1999;12(1):52-61. [PMID: 11847652]

30. Wardell DW, Weymouth KF. Review of studies of healing touch. J Nurs Scholarsh. 2004;36(2):147-54. [PMID: 15227762]

31. Keller E, Bzdek VM. Effects of therapeutic touch on tension headache pain. Nurs Res. 1986;35(2):101-6. [PMID: 3633503$]$

32. Bronfort G, Nilsson N, Haas M, Evans R, Goldsmith CH, Assendelft WJ, Bouter LM. Non-invasive physical treatments for chronic/recurrent headache. Cochrane Database Syst Rev. 2004;(3):CD001878. [PMID: 15266458]

33. Gordon A, Merenstein JH, D’Amico F, Hudgens D. The effects of therapeutic touch on patients with osteoarthritis of the knee. J Fam Pract. 1998;47(4):271-77. [PMID: 9789512]

34. Lin Y, Taylor AG. Effects of therapeutic touch in reducing pain and anxiety in an elderly population. Integr Med. 1998;1(4):155-62.

35. Eckes Peck SD. The effectiveness of therapeutic touch for decreasing pain in elders with degenerative arthritis. J Holist Nurs. 1997;15(2):176-98. [PMID: 9165806]

36. Denison B. Touch the pain away: New research on therapeutic touch and persons with fibromyalgia syndrome. Holist Nurs Pract. 2004;18(3):142-51. [PMID: 15222602]

37. Smith DW, Arnstein P, Rosa KC, Wells-Federman C. Effects of integrating therapeutic touch into a cognitive behavioral pain treatment program. Report of a pilot clinical trial. J Holist Nurs. 2002;20(4):367-87. [PMID: 12484105]

38. Olson K, Hanson J. Using Reiki to manage pain: A preliminary report. Cancer Prev Control. 1997;1(2):108-13. [PMID: 9765732]

39. Miles P. Preliminary report on the use of Reiki for HIVrelated pain and anxiety. Altern Ther Health Med. 2003; 9(2):36. [PMID: 12652881]

40. Olson K, Hanson J, Michaud M. A phase II trial of Reiki for the management of pain in advanced cancer patients. J Pain Symptom Manage. 2003;26(5):990-97. [PMID: 14585550]

41. Wu WH, Bandilla E, Ciccone DS, Yang J, Cheng SC, Carner N, Wu Y, Shen R. Effects of qigong on late-stage complex regional pain syndrome. Altern Ther Health Med. 1999;5(1):45-54. [PMID: 9893315]

42. Lee MS, Yang KH, Huh HJ, Kim HW, Ryu H, Lee HS, Chung HT. Qi therapy as an intervention to reduce chronic pain and to enhance mood in elderly subjects: A pilot study. Am J Chin Med. 2001;29(2):237-45. [PMID: 11527067]
43. Yang KH, Kim YH, Lee MS. Efficacy of Qi-therapy (external Qigong) for elderly people with chronic pain. Int J Neurosci. 2005;115(7):949-63. [PMID: 16051542]

44. Lee MS, Jang JW, Jang HS, Moon SR. Effects of Qitherapy on blood pressure, pain and psychological symptoms in the elderly: A randomized controlled pilot trial. Complement Ther Med. 2003;11(3):159-64.

[PMID: 14659379]

45. Cherkin DC, Eisenberg D, Sherman KJ, Barlow W, Kaptchuk TJ, Street J, Deyo RA. Randomized trial comparing traditional Chinese medical acupuncture, therapeutic massage, and self-care education for chronic low back pain. Arch Intern Med. 2001;161(8):1081-88. [PMID: 11322842]

46. Assendelft WJ, Morton SC, Yu EI, Suttorp MJ, Shekelle PG. Spinal manipulative therapy for low back pain. Cochrane Database Syst Rev. 2004;(1):CD000447. [PMID: 14973958]

47. Cherkin DC, Sherman KJ, Deyo RA, Shekelle PG. A review of the evidence for the effectiveness, safety, and cost of acupuncture, massage therapy, and spinal manipulation for back pain. Ann Intern Med. 2003;138(11):898-906. [PMID: 12779300$]$

48. Field TM. Massage therapy effects. Am Psychol. 1998; 53(12):1270-81. [PMID: 9872050]

49. Furlan AD, Brosseau L, Imamura M, Irvin E. Massage for low back pain. Cochrane Database Syst Rev. 2002;(2): CD001929. [PMID: 12076429]

50. Hernandez-Reif M, Field T, Krasnegor J, Theakston H. Lower back pain is reduced and range of motion increased after massage therapy. Int J Neurosci. 2001;106(3-4): 131-45. [PMID: 11264915]

51. Hsieh CY, Phillips RB, Adams AH, Pope MH. Functional outcomes of low back pain: Comparison of four treatment groups in a randomized controlled trial. J Manipulative Physiol Ther. 1992;15(1):4-9. [PMID: 1531488]

52. Pope MH, Phillips RB, Haugh LD, Hsieh CY, MacDonald L, Haldeman S. A prospective randomized threeweek trial of spinal manipulation, transcutaneous muscle stimulation, massage and corset in the treatment of subacute low back pain. Spine. 1994;19(22):2571-77. [PMID: 7855683]

53. Preyde M. Effectiveness of massage therapy for subacute low-back pain: A randomized controlled trial. CMAJ. 2000;162(13):1815-20. [PMID: 10906914]

54. Godfrey CM, Morgan PP, Schatzker J. A randomized trial of manipulation for low-back pain in a medical setting. Spine. 1984;9(3):301-4. [PMID: 6233718]

55. Hoehler FK, Tobis JS, Buerger AA. Spinal manipulation for low back pain. JAMA. 1981;245(18):1835-38. [PMID: 6453240] 
56. Melzack R, Vetere P, Finch L. Transcutaneous electrical nerve stimulation for low back pain. A comparison of TENS and massage for pain and range of motion. Phys Ther. 1983;63(4):489-93. [PMID: 6220415]

57. Nilsson N. A randomized controlled trial of the effect of spinal manipulation in the treatment of cervicogenic headache. J Manipulative Physiol Ther. 1995;18(7):435-40. [PMID: 8568424]

58. Nilsson N, Christensen HW, Hartvigsen J. The effect of spinal manipulation in the treatment of cervicogenic headache. J Manipulative Physiol Ther. 1997;20(5):326-30. [PMID: 9200048]

59. Wylie KR, Jackson C, Crawford PM. Does psychological testing help to predict the response to acupuncture or massage/relaxation therapy in patients presenting to a general neurology clinic with headache? J Tradit Chin Med. 1997; 17(2):130-39. [PMID: 10437184]

60. Irnich D, Behrens N, Molzen H, Konig A, Gleditsch J, Krauss M, Natalis M, Senn E, Beyer A, Schops P. Randomised trial of acupuncture compared with conventional massage and "sham" laser acupuncture for treatment of chronic neck pain. BMJ. 2001;322(7302):1574-78. [PMID: 11431299]

61. Dyson-Hudson TA, Shiflett SC, Kirshblum SC, Bowen JE, Druin EL. Acupuncture and Trager psychophysical integration in the treatment of wheelchair user's shoulder pain in individuals with spinal cord injury. Arch Phys Med Rehabil. 2001;82(8):1038-46. [PMID: 11494182]

62. Mok E, Woo CP. The effects of slow-stroke back massage on anxiety and shoulder pain in elderly stroke patients. Complement Ther Nurs Midwifery. 2004;10(4):209-16. [PMID: 15519938]

63. Van den Dolder PA, Roberts DL. A trial into the effectiveness of soft tissue massage in the treatment of shoulder pain. Aust J Physiother. 2003;49(3):183-88.

[PMID: 12952518]

64. Sunshine W, Field T, Schanberg S, Quintino O, Kilmer T, Fierro K, Kuhn C, Burman I. Massage therapy and transcutaneous electrical stimulation effects on fibromyalgia. J Clin Rheumatol. 1996;2:18-22.

65. Field T, Diego M, Cullen C, Hernandez-Reif M, Sunshine W, Douglas S. Fibromyalgia pain and substance $\mathrm{P}$ decrease and sleep improves after massage therapy. J Clin Rheumatol. 2002;8(2):72-76. [PMID: 17041326]

66. Brattberg G. Connective tissue massage in the treatment of fibromyalgia. Eur J Pain. 1999;3(3):235-44. [PMID: 10700351$]$

67. Alnigenis M, Bradley JD, Wallick J, Emsley CL. Massage therapy in the management of fibromyalgia: A pilot study. J Musculoskel Pain. 2001;9:55-67.
68. Walach H, Guthlin C, Konig M. Efficacy of massage therapy in chronic pain: A pragmatic randomized trial. J Altern Complement Med. 2003;9(6):837-46. [PMID: 14736355]

69. Hasson D, Arnetz B, Jelveus L, Edelstam B. A randomized clinical trial of the treatment effects of massage compared to relaxation tape recordings on diffuse long-term pain. Psychother Psychosom. 2004;73(1):17-24. [PMID: 14665792]

70. Plews-Ogan M, Owens JE, Goodman M, Wolfe P, Schorling J. A pilot study evaluating mindfulness-based stress reduction and massage for the management of chronic pain. J Gen Intern Med. 2005;20(12):1136-38. [PMID: 16423104$]$

71. Green C, Martin CW, Bassett K, Kazanjian A. A systematic review of craniosacral therapy: Biological plausibility, assessment reliability and clinical effectiveness. Complement Ther Med. 1999;7(4):201-7. [PMID: 10709302]

72. Hanten WP, Olson SC, Hodson JL, Imler VL, Knab VM, Magee JL. The effectiveness of CV-4 and resting position techniques on subjects with tension-type headaches. J Man Manipulative Ther. 1999;7(2):64-70.

73. Upledger JE, Vredevoogd JD. Craniosacral therapy. Chicago (IL): Eastland Press; 1987.

74. Fernandez-de-Las-Penas C, Alonso-Blanco C, Cuadrado ML, Miangolarra JC, Barriga FJ, Pareja JA. Are manual therapies effective in reducing pain from tension-type headache?: A systematic review. Clin J Pain. 2006;22(3): 278-85. [PMID: 16514329]

75. Inayat Khan PV. Awakening: A Sufi experience. New York (NY): Jeremy P. Tarcher/Putnam; 1999.

76. Kaplan A. Meditation and Kabbalah. New York (NY): Samuel Weiser; 1982.

77. Keating T. Open mind, open heart. New York (NY): Amity House; 1986.

78. Astin JA, Berman BM, Bausell B, Lee WL, Hochberg M, Forys KL. The efficacy of mindfulness meditation plus Qigong movement therapy in the treatment of fibromyalgia: A randomized controlled trial. J Rheumatol. 2003; 30(10):2257-62. [PMID: 14528526]

79. Marlatt GA, Kristeller JL. Mindfulness and meditation. In: Miller WR, editor. Integrating spirituality into treatment: Resources for practitioners. Washington (DC): American Psychological Association; 1999. p. 67-84.

80. Brown KW, Ryan RM. The benefits of being present: Mindfulness and its role in psychological well-being. J Pers Soc Psychol. 2003;84(4):822-48. [PMID: 12703651]

81. Kabat-Zinn J, Lipworth L, Burney R. The clinical use of mindfulness meditation for the self-regulation of chronic pain. J Behav Med. 1985;8(2):163-90. [PMID: 3897551]

82. Kabat-Zinn J. An outpatient program in behavioral medicine for chronic pain patients based on the practice of mindfulness meditation: Theoretical considerations and 
preliminary results. Gen Hosp Psychiatry. 1982;4(1):33-47. [PMID: 7042457]

83. Astin JA. Mind-body therapies for the management of pain. Clin J Pain. 2004;20(1):27-32. [PMID: 14668653]

84. Kabat-Zinn J, Lipworth L, Burney R, Sellers W. Fouryear follow-up of a meditation-based program for the selfregulation of chronic pain: Treatment outcomes and compliances. Clin J Pain. 1986;2(3):159-73.

85. Grossman P, Niemann L, Schmidt S, Walach H. Mindfulness-based stress reduction and health benefits. A metaanalysis. J Psychosom Res. 2004;57(1):35-43. [PMID: 15256293]

86. Carson JW, Keefe FJ, Lynch TR, Carson KM, Goli V, Fras AM, Thorp SR. Loving-kindness meditation for chronic low back pain: Results from a pilot trial. J Holist Nurs. 2005;23(3):287-304. [PMID: 16049118]

87. Mehling WE, Hamel KA, Acree M, Byl N, Hecht FM. Randomized, controlled trial of breath therapy for patients with chronic low-back pain. Altern Ther Health Med. 2005; 11(4):44-52. [PMID: 16053121]

88. Astin JA, Shapiro SL, Eisenberg DM, Forys KL. Mind-body medicine: State of the science, implications for practice. J Am Board Fam Pract. 2003;16(2):131-47. [PMID: 12665179]

89. Keefer L, Blanchard EB. The effects of relaxation response meditation on the symptoms of irritable bowel syndrome: Results of a controlled treatment study. Behav Res Ther. 2001;39(7):801-11. [PMID: 11419611]

90. Jensen MP, Patterson DR. Hypnotic treatment of chronic pain. J Behav Med. 2006;29(1):95-124. [PMID: 16404678]

91. Maurischat C, Harter M, Kerns RD, Bengel J. Further support for the pain stages of change model: Suggestions for improved measurement. Eur J Pain. 2006;10(1):41-49. [PMID: 16291297]

92. Bormann JE, Smith TL, Becker S, Gershwin M, Pada L, Grudzinski AH, Nurmi EA. Efficacy of frequent mantram repetition on stress, quality of life, and spiritual wellbeing in veterans: A pilot study. J Holist Nurs. 2005; 23(4):395-414. [PMID: 16251489]

93. Heide FJ, Borkovec TD. Relaxation-induced anxiety: Paradoxical anxiety enhancement due to relaxation training. J Consult Clin Psychol. 1983;51(2):171-82. [PMID: 6341426]

94. Green JP, Barabasz AF, Barrett D, Montgomery GH. Forging ahead: The 2003 APA Division 30 definition of hypnosis. Int J Clin Exp Hypn. 2005;53(3):259-64. [PMID: 16076663]

95. Patterson DR, Jensen MP. Hypnosis and clinical pain. Psychol Bull. 2003;129(4):495-521. [PMID: 12848218]

96. Montgomery GH, DuHamel KN, Redd WH. A metaanalysis of hypnotically induced analgesia: How effective is hypnosis? Int J Clin Exp Hypn. 2000;48(2):138-53. [PMID: 10769981]

97. Jensen MP, McArthur KD, Barber J, Hanley MA, Engel JM, Romano JM, Cardenas DD, Kraft GH, Hoffman AJ, Patterson DR. Satisfaction with, and the beneficial side effects of, hypnotic analgesia. Int J Clin Exp Hypn. 2006;54(4):432-47. [PMID: 16950685]

98. Iyengar BKS. Light on yoga. New York (NY): Shocken Press; 1979.

99. Williams KA, Petronis J, Smith D, Goodrich D, Wu J, Ravi N, Doyle EJ Jr, Juckett RG, Munoz Kolar M, Gross $\mathrm{R}$, Steinberg L. Effect of Iyengar yoga therapy for chronic low back pain. Pain. 2005;115(1-2):107-17. [PMID: 15836974]

100. Sherman KJ, Cherkin DC, Erro J, Miglioretti DL, Deyo RA. Comparing yoga, exercise, and a self-care book for chronic low back pain: A randomized, controlled trial. Ann Intern Med. 2005;143(12):849-56. [PMID: 16365466$]$

101. Galantino ML, Bzdewka TM, Eissler-Russo JL, Holbrook ML, Mogck EP, Geigle P, Farrar JT. The impact of modified Hatha yoga on chronic low back pain: A pilot study. Altern Ther Health Med. 2004;10(2):56-59.

[PMID: 15055095$]$

102. Jacobs BP, Mehling W, Avins AL, Goldberg HA, Acree M, Lasater JH, Cole RJ, Riley DS, Maurer S. Feasibility of conducting a clinical trial on Hatha yoga for chronic low back pain: Methodological lessons. Altern Ther Health Med. 2004;10(2):80-83. [PMID: 15055099] Erratum in: Altern Ther Health Med. 2004;10(3):48.

103. Garfinkel MS, Singhal A, Katz WA, Allan DA, Reshetar R, Schumacher HR Jr. Yoga-based intervention for carpal tunnel syndrome: A randomized trial. JAMA. 1998;280(18): 1601-3. [PMID: 9820263]

104. Garfinkel MS, Schumacher HR Jr, Husain A, Levy M, Reshetar RA. Evaluation of a yoga based regimen for treatment of osteoarthritis of the hands. J Rheumatol. 1994;21(12):2341-43. [PMID: 7699639]

105. Sherman RA. Biofeedback. In: Leskowitz E, editor. Complementary and alternative medicine in rehabilitation. New York (NY): Churchill Livingstone; 2003. p. 125-38.

106. Tan G, Sherman R, Shanti B. Biofeedback pain interventions. Pract Pain Manage. 2003;3:12-18.

107. Blanchard EB, Andrasik F. Management of chronic headaches. New York (NY): Pergamon Press; 1985.

108. Blanchard EB, Greene B, Scharff L, Schwarz-McMorris SP. Relaxation training as a treatment for irritable bowel syndrome. Biofeedback Self Regul. 1993;18(3):125-32. [PMID: 8218507]

109. Nestoriuc Y, Martin A. Efficacy of biofeedback for migraine: A meta-analysis. Pain. 2007;128(1-2):111-27. [PMID: 17084028] 
110. Rains JC, Penzien DB, McCrory DC, Gray RN. Behavioral headache treatment: History, review of the empirical literature, and methodological critique. Headache. 2005; 45(Suppl 2):S92-109. [PMID: 15921506]

111. Blanchard EB, Hillhouse J, Appelbaum KA, Jaccard J. What is an adequate length of baseline in research and clinical practice with chronic headache? Biofeedback Self Regul. 1987;12(4):323-29. [PMID: 3331299]

112. Gevirtz RN, Glaros AG, Hopper D, Schwartz MS. Temporomandibular disorders. In: Schwartz M, editor. Biofeedback: A practitioner's guide. 2nd ed. New York (NY): Guilford Press; 1995. p. 411-28.

113. Dahlstrom L, Carlsson SG. Treatment of mandibular dysfunction: The clinical usefulness of biofeedback in relation to splint therapy. J Oral Rehabil. 1984;11(3):277-84. [PMID: 6588179]

114. Hijzen TH, Slangen JL, van Houweligen HC. Subjective, clinical and EMG effects of biofeedback and splint treatment. J Oral Rehabil. 1986;13(6):529-39. [PMID: 3467047]

115. Crider A, Glaros AG, Gevirtz RN. Efficacy of biofeedback-based treatments for temporomandibular disorders. Appl Psychophysiol Biofeedback. 2005;30(4):333-45. [PMID: 16385422]

116. Neblett R, Gatchel RJ, Mayer TG. A clinical guide to surface-EMG-assisted stretching as an adjunct to chronic musculoskeletal pain rehabilitation. Appl Psychophysiol Biofeedback. 2003;28(2):147-60. [PMID: 12827993]

117. Newton-John TR, Spence SH, Schotte D. Cognitivebehavioural therapy versus EMG biofeedback in the treatment of chronic low back pain. Behav Res Ther. 1995; 33(6):691-97. [PMID: 7654161]

118. Van Tulder MW, Koes B, Malmivaara A. Outcome of non-invasive treatment modalities on back pain: An evidence-based review. Eur Spine J. 2006;15(Suppl 1):S64-81. [PMID: 16320031]

119. Van Tulder MW, Ostelo R, Vlaeyen JW, Linton SJ, Morley SJ, Assendelft WJ. Behavioral treatment for chronic low back pain: A systematic review within the framework of the Cochrane Back Review Group. Spine. 2001;26(3): 270-81. [PMID: 11224863]

120. Flor H, Birbaumer N. Comparison of the efficacy of electromyographic biofeedback, cognitive-behavioral therapy, and conservative medical interventions in the treatment of chronic musculoskeletal pain. J Consult Clin Psychol. 1993;61(4):653-58. [PMID: 8370861]

121. Sherman RA, Devor M, Heermann-Do K. Phantom pain. New York (NY): Plenum Press; 1997.

122. Belleggia G, Birbaumer N. Treatment of phantom limb pain with combined EMG and thermal biofeedback: A case report. Appl Psychophysiol Biofeedback. 2001;26(2): 141-46. [PMID: 11480164]
123. Harden RN, Houle TT, Green S, Remble TA, Weinland SR, Colio S, Lauzon J, Kuiken T. Biofeedback in the treatment of phantom limb pain: A time-series analysis. Appl Psychophysiol Biofeedback. 2005;30(1):83-93. [PMID: 15889588]

124. Donaldson CC, MacInnis AL, Snelling LS, Sella GE, Mueller HH. Characteristics of diffuse muscular coactivation (DMC) in persons with fibromyalgia-Part 2. NeuroRehabilitation. 2002;17(1):41-48. [PMID: 12016346]

125. Donaldson CC, Snelling LS, MacInnis AL, Sella GE, Mueller HH. Diffuse muscular coactivation (DMC) as a potential source of pain in fibromyalgia-Part 1. NeuroRehabilitation. 2002;17(1):33-39. [PMID: 12016345$]$

126. Mueller HH, Donaldson CC, Nelson DV, Layman M. Treatment of fibromyalgia incorporating EEG-Driven stimulation: A clinical outcomes study. J Clin Psychol. 2001;57(7):933-52. [PMID: 11406805]

127. Sherman RA. Pain assessment and intervention from a psychological perspective. Assoc Appl Psychophysiol Biofeedback. 2003.

128. Shipley M, Berry H, Broster G, Jenkins M, Clover A, Williams I. Controlled trial of homoeopathic treatment of osteoarthritis. Lancet. 1983;1(8316):97-98.

[PMID: 6129459]

129. Stam C, Bonnet MS, van Haselen RA. The efficacy and safety of a homeopathic gel in the treatment of acute low back pain: A multi-centre, randomised, double-blind comparative clinical trial. Br Homeopath J. 2001;90(1):21-28. [PMID: 11212085]

130. Van Haselen RA, Fisher PA. A randomized controlled trial comparing topical piroxicam gel with a homeopathic gel in osteoarthritis of the knee. Rheumatology (Oxford). 2000;39(7):714-19. [PMID: 10908688]

131. U, Springer W, Stritzl G, Gaus W, Haag G. Classical homeopathic treatment of chronic headaches. Cephalalgia. 1997; 17(2):119-26; discussion 101.

[PMID: 9137850]

132. Gibson RG, Gibson SL, MacNeill AD, Buchanan WW. Homoeopathic therapy in rheumatoid arthritis: Evaluation by double-blind clinical therapeutic trial. Br J Clin Pharmacol. 1980;9(5):453-59. [PMID: 6994789]

133. Birch S, Hesselink JK, Jonkman FA, Hekker TA, Bos A. Clinical research on acupuncture. Part 1 . What have reviews of the efficacy and safety of acupuncture told us so far? J Altern Complement Med. 2004;10(3):468-80. [PMID: 15253851]

134. Furlan AD, Van Tulder M, Cherkin D, Tsukayama H, Lao L, Koes B, Berman B. Acupuncture and dry-needling for low back pain: An updated systematic review within the framework of the Cochrane Collaboration. Spine. 2005; 30(8):944-63. [PMID: 15834340] 
135. Manheimer E, White A, Berman B, Forys K, Ernst E. Meta-analysis: Acupuncture for low back pain Ann Intern Med. 2005;142(8):651-63. [PMID: 15838072] Erratum in: Ann Intern Med. 2005;142(11):950-51.

136. Yu JN, Liu BY, Liu ZS, Robinson V. Evaluation of clinical therapeutic effects and safety of acupuncture treatment for premenstrual syndrome [Chinese]. Zhongguo Zhen Jiu. 2005;25(6):377-82. [PMID: 16309077]

137. Gilron I, Max MB. Combination pharmacotherapy for neuropathic pain: Current evidence and future directions. Expert Rev Neurother. 2005;5(6):823-30. [PMID: 16274339]

138. Chung A, Bui L, Mills E. Adverse effects of acupuncture. Which are clinically significant? Can Fam Physician. 2003;49:985-89. [PMID: 12943357]

139. Ernst G, Strzyz H, Hagmeister H. Incidence of adverse effects during acupuncture therapy-A multicentre survey. Complement Ther Med. 2003;11(2):93-97. [PMID: 12801494$]$

140. Filshie J. Safety aspects of acupuncture in palliative care. Acupunct Med. 2001;19(2):117-22. [PMID: 11829159]

141. MacPherson H, Thomas K, Walters S, Fitter M. A prospective survey of adverse events and treatment reactions following 34,000 consultations with professional acupuncturists. Acupunct Med. 2001;19(2):93-102. [PMID: 11829165$]$

142. Giordano J, Garcia MK, Boatwright D, Klein K. Complementary and alternative medicine in mainstream public health: A role for research in fostering integration. J Altern Complement Med. 2003;9(3):441-45. [PMID: 12816632]

143. Giordano J, Engebretson J, Garcia MK. Challenges to complementary and alternative medical research: Focal issues influencing integration into a cancer care model. Integr Cancer Ther. 2005;4(3):210-18. [PMID: 16113028]

144. Fugh-Berman A. Herb-drug interactions. Lancet. 2000; 355(9198):134-38. [PMID: 10675182] Erratum in: Lancet. 2000;355(9208):1020.

145. Hu Z, Yang X, Ho PC, Chan SY, Heng PW, Chan E, Duan W, Koh HL, Zhou S. Herb-drug interactions: A literature review. Drugs. 2005;65(9):1239-82. [PMID: 15916450]

146. Tan G, Alvarez J, Jensen MP. Complementary and alternative medicine approaches to pain management. J Clin Psychol. 2006;62(11)1419-31. [PMID: 16937354]

147. Giordano J. The neuroscience of pain and analgesia. In: Boswell MV, Cole BE, editors. Weiner's pain management: A guide for clinicians. 7th ed. Boca Raton (FL): Taylor \& Francis; 2005. p. 15-34.

148. Giordano J. Understanding pain as disease and illness. Pract Pain Manage. 2006;6(6):70-73.

149. Giordano J. Pain research: Can paradigmatic expansion bridge the demands of medicine, scientific philosophy and ethics? Pain Physician. 2004;7(4):407-10. [PMID: 16858480]

150. Giordano J. Good as gold? The randomized controlled trial: Paradigmatic revision and responsibility in pain research. Am J Pain Manage. 2006;16(2):66-69.

151. PDR Health [homepage on the Internet]. Stamford (CT): Thomson Corporation; c2006 [updated 2007; cited 2007 Mar 12]. Glucosamine [1 screen]. Available from http:// www.pdrhealth.com/

152. Setnikar I, Rovati LC. Absorption, distribution, metabolism and excretion of glucosamine sulfate. A review. Arzneimittelforschung. 2001;51(9):699-725. [PMID: 11642003$]$

153. Pavelka K, Gatterova J, Olejarova M, Machacek S, Giacovelli G, Rovati LC. Glucosamine sulfate use and delay of progression of knee osteoarthritis: A 3-year, randomized, placebo-controlled, double-blind study. Arch Intern Med. 2002;162(18):2113-23. [PMID: 12374520]

154. Towheed TE, Anastassiades TP. Glucosamine and chondroitin for treating symptoms of osteoarthritis: Evidence is widely touted but incomplete. JAMA. 2000;283(11): 1483-84. [PMID: 10732941]

155. PDR Health [homepage on the Internet]. Stamford (CT): Thomson Corporation; c2006 [updated 2007; cited 2007 Mar 12]. Chondroitin sulfate [1 screen]. Available from http://www.pdrhealth.com/

156. Ross J. Biological effects of pulsed high peak power: Electromagnetic energy using Diapulse. In: O’Connor ME, Bentall RH, Monahan JC, editors. Emerging electromagnetic medicine. New York (NY): Springer Verlag; 1990. p. 269-82.

157. Fenn JE. Effect of pulsed electromagnetic energy (Diapulse) on experimental hematomas. Can Med Assoc J. 1969; 100(5):251-54. [PMID: 5304132]

158. Freedman RR. Physiological mechanisms of temperature biofeedback. Biofeedback Self Regul. 1991;16(2):95-115. [PMID: 1854864$]$

159. Giordano J. How Alpha-Stim cranial electrotherapy stimulation (CES) works. Mineral Wells (TX): Electromedical Products International, Inc; 2006.

160. Rogers ME. Nursing: A science of unitary human beings. In: Riehl-Sisca J, editor. Conceptual models for nursing practice. 3rd ed. Norwalk (CT): Appleton \& Lange; 1989. p. 181-88.

161. Meehan TC. Therapeutic touch and postoperative pain: A Rogerian research study. Nurs Sci Q. 1993;6(2):69-78. [PMID: 8502438]

162. Maigne JY, Vautravers P. Mechanism of action of spinal manipulative therapy. Joint Bone Spine. 2003;70(5):336-41. [PMID: 14563460]

163. National Center for Complementary and Alternative Medicine [homepage on the Internet]. Washington (DC): National Institutes of Health; c2003 [updated 2006 Mar 
JRRD, Volume 44, Number 2, 2007

23; cited 2007 Mar 12]. About chiropractic and its use in treating low back pain [1 screen]. Available from: http:// nccam.nih.gov/

164. Melzack R, Wall PD. Pain mechanisms: A new theory. Science. 1965;150(699):971-79. [PMID: 5320816]

165. Field TM, Sunshine W, Hernandez-Reif M, Quintino O, Schanberg S, Kuhn C, Burman I. Massage therapy effects on depression and somatic symptoms in chronic fatigue syndrome. J Chronic Fatigue Syndr. 1997;3(3):43-52.

166. Benson H, Greenwood MM, Klemchuk H. The relaxation response: Psychophysiologic aspects and clinical applications. Int J Psychiatry Med. 1975;6(1-2):87-98.

[PMID: 773864]

167. Stefano GB, Esch T. Integrative medical therapy: Examination of meditation's therapeutic and global medicinal outcomes via nitric oxide (review). Int J Mol Med. 2005;16(4):621-30. [PMID: 16142396]

168. Dusek JA, Chang BH, Zaki J, Lazar S, Deykin A, Stefano GB, Wohlhueter AL, Hibberd PL, Benson H. Association between oxygen consumption and nitric oxide production during the relaxation response. Med Sci Monit. 2006; 12(1):CR1-10. [PMID: 16369463]

169. Hofbauer RK, Rainville P, Duncan GH, Bushnell MC. Cognitive modulation of pain sensation alters activity in human cerebral cortex. Soc Neurosci Abstr. 1998;24:1135.

170. Rainville P, Duncan GH, Price DD, Carrier B, Bushnell MC. Pain affect encoded in human anterior cingulate but not somatosensory cortex. Science. 1997;277(5328):968-71. [PMID: 9252330]

171. Rainville P, Carrier B, Hofbauer RK, Bushnell MC, Duncan GH. Dissociation of sensory and affective dimensions of pain using hypnotic modulation. Pain. 1999;82(2):159-71. [PMID: 10467921]

172. Danziger N, Fournier E, Bouhassira D, Michaud D, De Broucker T, Santarcangelo E, Carli G, Chertock L, Willer JC. Different strategies of modulation can be operative during hypnotic analgesia: A neurophysiological study. Pain. 1998;75(1):85-92. [PMID: 9539677]

173. Kiernan BD, Dane JR, Phillips LH, Price DD. Hypnotic analgesia reduces R-III nociceptive reflex: Further evidence concerning the multifactorial nature of hypnotic analgesia. Pain. 1995;60(1):39-47. [PMID: 7715940]

174. McNulty WH, Gevirtz RN, Hubbard DR, Berkoff GM. Needle electromyographic evaluation of trigger point response to a psychological stressor. Psychophysiology. 1994;31(3):313-16. [PMID: 8008795]

175. National Center for Complementary and Alternative Medicine [homepage on the Internet]. Washington (DC): National Institutes of Health; c2003 [updated 2006 Jun 27; cited 2006 Mar 8]. Questions and answers about homeopathy [1 screen]. Available from: http://nccam.nih.gov/

176. Stehlin I. Homeopathy: Real medicine or empty promise. FDA Consumer. 1996;30(10):15.

177. Takeshige C. Mechanism of acupuncture analgesia based on animal experiments. In: Pomerantz B, Stux G, editors. Scientific bases of acupuncture. Berlin (Germany): SpringerVerlag; 1989.

178. Lee BY, LaRiccia PJ, Newberg AB. Acupuncture in theory and practice. Hosp Physician. 2004;40:11-18.

Submitted for publication June 9, 2006. Accepted in revised form March 12, 2007. 